\title{
Assessment of Left Ventricular Myocardial Diseases with Cardiac Computed Tomography
}

\author{
Sung Min Ko, $M D^{1}$, Tae Hoon Kim, $M D^{2}$, Eun Ju Chun, $M D^{3}$, Jin Young Kim, $M D^{4}$, Sung Ho Hwang, $M D^{5}$ \\ ${ }^{1}$ Department of Radiology, Konkuk University Medical Center, Konkuk University School of Medicine, Seoul, Korea; ${ }^{2}$ Department of Radiology, \\ Gangnam Severance Hospital, Yonsei University College of Medicine, Seoul, Korea; ${ }^{3}$ Department of Radiology, Seoul National University Bundang \\ Hospital, Seongnam, Korea; ${ }^{2}$ Department of Radiology, Dongsan Medical Center, Keimyung University College of Medicine, Daegu, Korea; \\ ${ }^{5}$ Department of Radiology, Korea University Anam Hospital, Seoul, Korea
}

Rapid advances in cardiac computed tomography (CT) have enabled the characterization of left ventricular (LV) myocardial diseases based on LV anatomical morphology, function, density, and enhancement pattern. Global LV function and regional wall motion can be evaluated using multi-phasic cine CT images. CT myocardial perfusion imaging facilitates the identification of hemodynamically significant coronary artery disease. CT delayed-enhancement imaging is used to detect myocardial scar in myocardial infarction and to measure the extracellular volume fraction in non-ischemic cardiomyopathy. Multi-energy cardiac CT allows the mapping of iodine distribution in the myocardium. This review summarizes the current techniques of cardiac CT for LV myocardial assessment, highlights the key findings in various myocardial diseases, and presents future applications to complement echocardiography and cardiovascular magnetic resonance.

Keywords: Computed tomography; Myocardium; Myocardial perfusion imaging; Delayed enhancement

\section{INTRODUCTION}

Increased awareness of left ventricular (LV) myocardial disease is attributed to the widespread use of noninvasive imaging modalities (1). Echocardiography is still a cornerstone of LV diagnostic imaging because it can provide a safe and comprehensive assessment of cardiac structure, function, and regional wall motion. However, echocardiography is operator-dependent, with a relatively low reproducibility, and possible impairment due to a poor acoustic window, limited field of vision, and technical artifacts (2). Cardiovascular magnetic resonance (CMR) is considered the current gold standard for LV morphological

Received May 2, 2018; accepted after revision 0ctober 3, 2018. Corresponding author: Sung Min Ko, MD, Department of Radiology, Konkuk University Medical Center, Konkuk University School of Medicine, 120-1 Neungdong-ro, Gwangjin-gu, Seoul 05030, Korea.

- Tel: (822) 2030-5578 • Fax: (822) 447-8726

-E-mail:ksm9723@yahoo.co.kr

This is an Open Access article distributed under the terms of the Creative Commons Attribution Non-Commercial License (https://creativecommons.org/licenses/by-nc/4.0) which permits unrestricted non-commercial use, distribution, and reproduction in any medium, provided the original work is properly cited. and functional assessment due to its accurate measurements of the entire volume and mass without echo-window dependency. In addition, it has a unique role in noninvasive tissue characterization using different pulse sequences $(3,4)$.

In the last decade, rapid technical advances in computed tomography (CT) have led to the emergence of cardiac CT (CCT) as a comprehensive evaluation of anatomy and function including the coronary arteries and cardiac chambers. Although CCT is not recommended as the primary method of choice in cases of suspected LV myocardial diseases, CT enables multiplanar reconstructions in any desired orientation and can evaluate the echo-window limited areas such as the apex, the posterior portion of the interventricular septum, and the anterolateral wall. Therefore, CCT offers a comprehensive insight into the anatomy and function of cardiac chambers (5). Recent studies have demonstrated that CCT may be an attractive imaging tool for the characterization of LV myocardial diseases based on gross morphology, function, and enhancement, as well as the extracellular volume fraction (ECV). Therefore, CCT is considered complementary to echocardiography and $\operatorname{CMR}(1,6)$. In this review, the current techniques and uses of CCT for LV myocardial assessment 
are discussed. The roles of CCT imaging in the diagnosis of LV myocardial diseases have also been highlighted.

\section{Anatomical Assessment of the Left Ventricle with CCT}

The left ventricle is a conical structure with thick tubular walls tapering to a rounded apex. It comprises an inlet portion containing the mitral valve and its tension apparatus, an apical portion containing fine trabeculations, and an outlet portion leading to the aortic valve.

Normally, the LV free wall is thickest at the cardiac base. The ventricular septum is curved, bulging into the right ventricular cavity. It is muscular except for a small portion immediately beneath the aortic valve (the membranous septum). When the left ventricle is viewed in shortaxial cuts, the mitral valve is supported by two groups of papillary muscles in the anterolateral and posteromedial positions. The bases of the papillary muscles are continuous with the muscular trabeculations at the middle-to-apical third of the ventricular wall (Fig. 1) (7-9).

The LV wall consists of three distinct layers: an inner endocardium, a middle myocardium, and an outer epicardium. The myocardium consists primarily of contractile cardiac myocytes, fibroblasts, and an abundant extracellular matrix. The left ventricle is subdivided into three main segments: the apical, middle, and basal portions. This standardized and widely used segmentation of the left ventricle into 17 myocardial segments was introduced by the American Heart Association (10). The different anatomic landmarks partially reflect the distribution of perfusion of the myocardium by the coronary arteries.

\section{Technical Aspects of CCT}

There are two methods to obtain CCT images according to electrocardiography (ECG)-gating techniques. In prospective ECG-triggered sequential scanning in a "stepand-shoot" technique, the CT images are acquired in a user-selected phase of the patient's cardiac cycle (usually during mid-diastole). This technique does not allow for the evaluation of LV function and wall motion (Fig. 2). With the retrospective ECG-gated spiral scanning based on continuous data acquisition and table movement at low table feed (low spiral pitch) or ECG-gated volumetric acquisition with a static table (256- and 320-detector-row CT scanner), CT images are obtained at multiple phases of the cardiac cycle for the assessment of LV functional parameters including wall thickness, volume, and mass, and identification of LV regional wall motion abnormality (11-13).

LV volumes and function are evaluated using a triphasic injection protocol to opacify all the cardiac chambers without streak artifact in the superior vena cava. The total contrast volume is usually $50-120 \mathrm{~mL}$. An initial contrast media bolus at $5-7 \mathrm{~mL} / \mathrm{s}$ is followed by either a slower rate of contrast media injection at $2 \mathrm{~mL} / \mathrm{s}$ or a $50 \%: 50 \%$ saline/
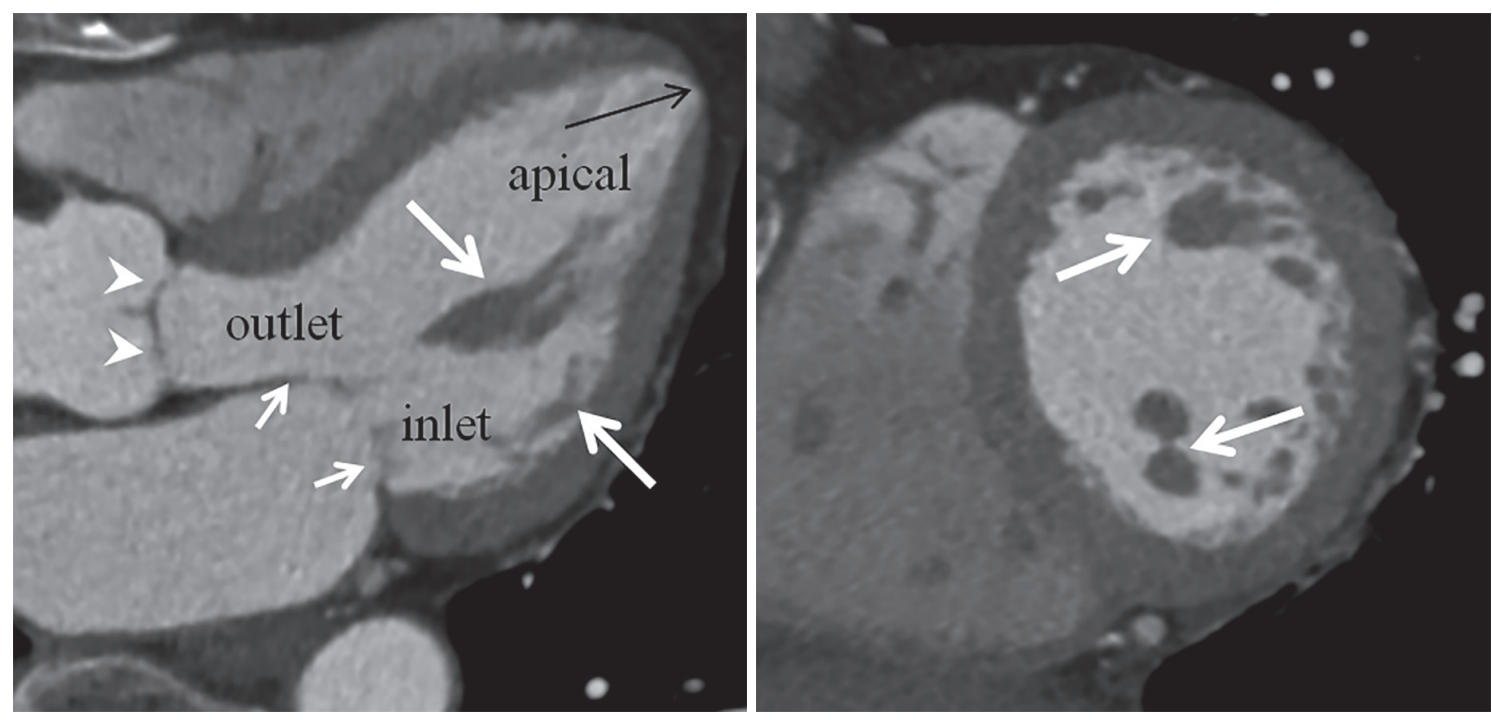

A

B

Fig. 1. Anatomy of left ventricle.

Three-chamber (A) and short-axis (B) MPR CCT images show mitral valve (short arrows), aortic valve (arrowheads), papillary muscles (thick arrows), and apical thinning (long arrow). Left ventricle is divided into three portions: inlet, apical, and outlet. Short-axis MPR image (B) is obtained at midventricular level. CCT = cardiac computed tomography, MPR = multiplanar reformat 

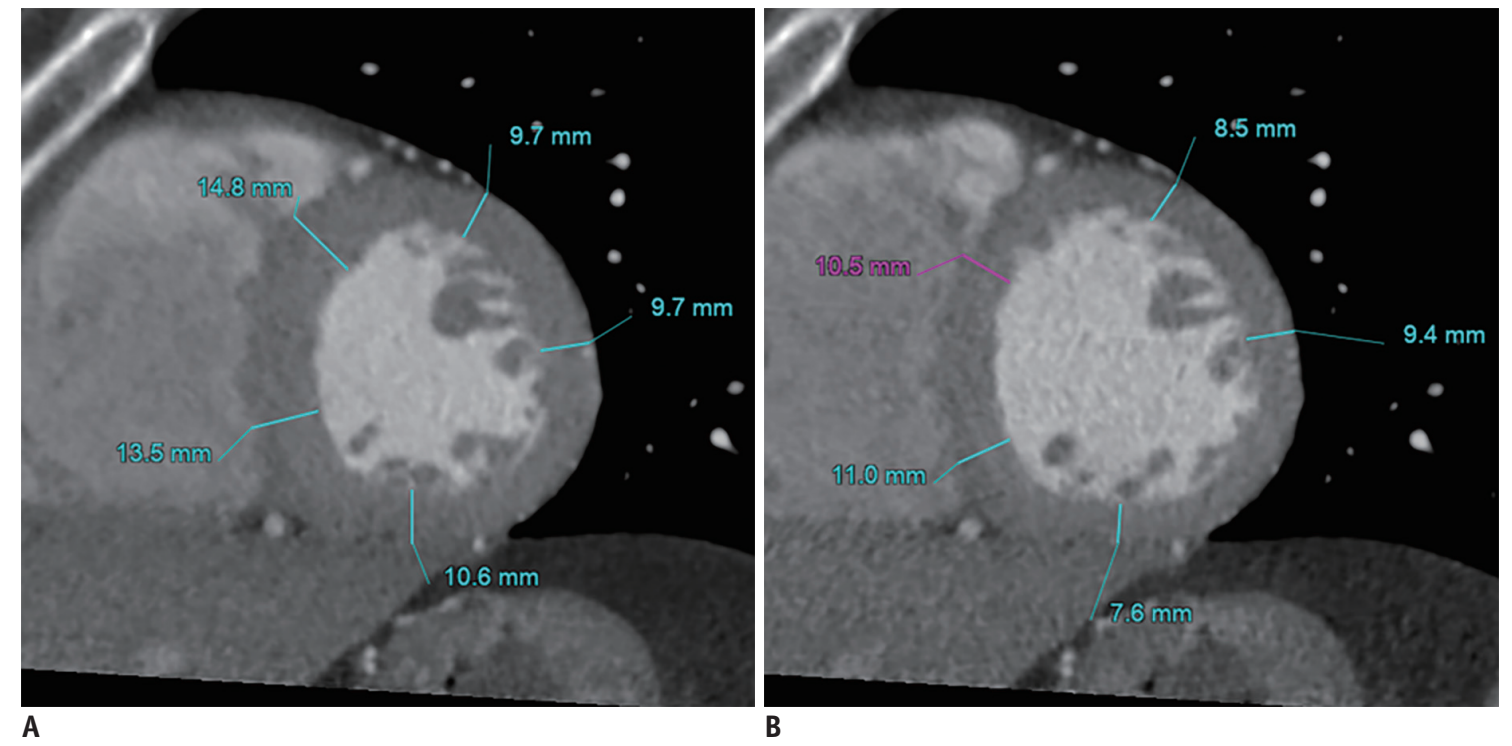

Fig. 2. Changes in LV wall thickness during mid- and end-diastole.

Wall thickness and chamber dimension of left ventricle need precise measurements, usually in end-diastole. Most CCT is performed in mid-diastole to evaluate coronary artery. Interpretation of LV wall thickness may be misleading in mid-diastole (A) compared with that in end-diastole (B). $\mathrm{LV}=$ left ventricular

contrast media mixture at $5-7 \mathrm{~mL} / \mathrm{s}$ and a smaller volume saline bolus (14). Routine CCT is typically acquired during the early arterial phase for coronary artery assessment. However, to ensure sufficient myocardial enhancement, the timing of image acquisition is calculated by adding approximately 2-4 seconds to the measured time of peak aortic root enhancement (usually 100-150 Hounsfield units [HU]) (15).

Currently, CT perfusion has evolved into a robust and non-invasive tool for the detection of myocardial ischemia. There are two approaches-static and dynamic-in perfusion CT. Static perfusion CT provides a snapshot of the myocardial blood volume or myocardial enhancement at a single time point during the first-pass of contrast material bolus. A true perfusion defect persists throughout multiple phases and it is visualized in both systole and diastole. These data are also used to identify regional LV wall motion abnormality. Static perfusion CT is easily performed on any CCT scanner although it is highly dependent on the timing of the scan. In addition, cardiac motion artifacts due to increased heart rate during adenosine stress have shown a significant percentage of patients in static perfusion $\mathrm{CT}$. On the other hand, the dynamic first-pass perfusion CT reveals myocardial enhancement at multiple time points during first-pass of the contrast material and it facilitates quantitative analysis of myocardial perfusion. The best cutoff myocardial blood flow value distinguishing ischemic from remote myocardium varies from 75 to $103 \mathrm{~mL} / 100$ $\mathrm{mL} / \mathrm{min}$. However, the drawbacks of dynamic perfusion $\mathrm{CT}$ imaging include higher exposure to radiation (than static perfusion CT) and the limited use of CT scanners (256- or 320-detector-row CT scanners and dual-source Somatom Flash and Force CT scanners [Siemens Healthcare, Forchheim, Germany]) (16-18).

Delayed-enhancement CCT shares similar pathophysiological basis with delayed-enhancement CMR and it facilitates the evaluation of LV myocardial viability or scarring with additional administration of contrast medium (slow injection rate of up to $2 \mathrm{~mL} / \mathrm{s}$ and volume between 50 and $90 \mathrm{~mL}$ ). A delayed scan is usually performed after a variable period of 5-15 minutes following the initial administration of contrast medium. The amount of contrast medium, injection rate, and the delay time are adjusted on a case-by-case basis to evaluate for delayed myocardial enhancement $(19,20)$. Decreased tube voltage (100 or 80 $\mathrm{kVp}$ ) and prospective ECG triggering reduce the radiation exposure and increase the myocardial contrast in delayedphase CCT even though the image noise is increased. Delayed hyperenhancement is attributed to the slow washout of iodinated contrast media from the region of infarcted myocardium (Fig. 3) (19-21). Mahnken et al. (22) and Gerber et al. (23) showed that delayed-enhancement CCT imaging can be used to quantify infarct size strongly correlated with CMR-based imaging. ECV is a reproducible and novel index for assessment of myocardial fibrosis and it is calculated as a ratio of the change in $\mathrm{HU}$ of the myocardium and the LV blood before (pre-contrast CCT) and 


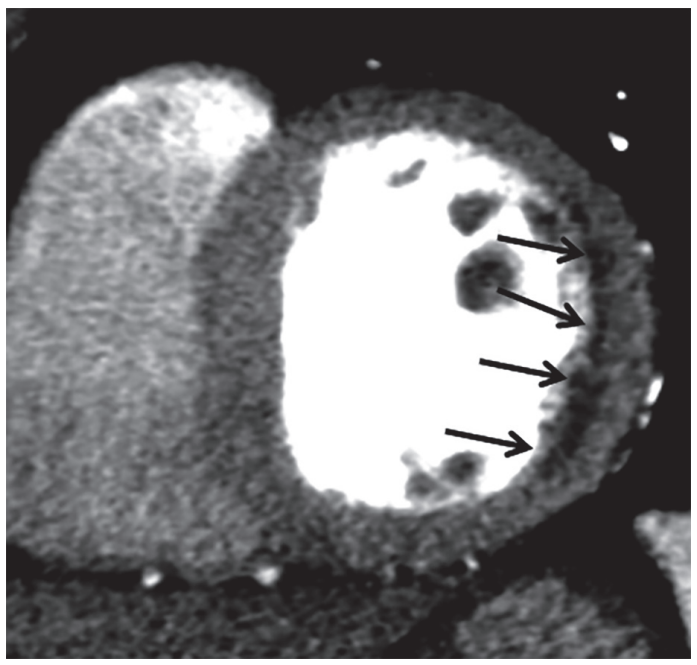

A

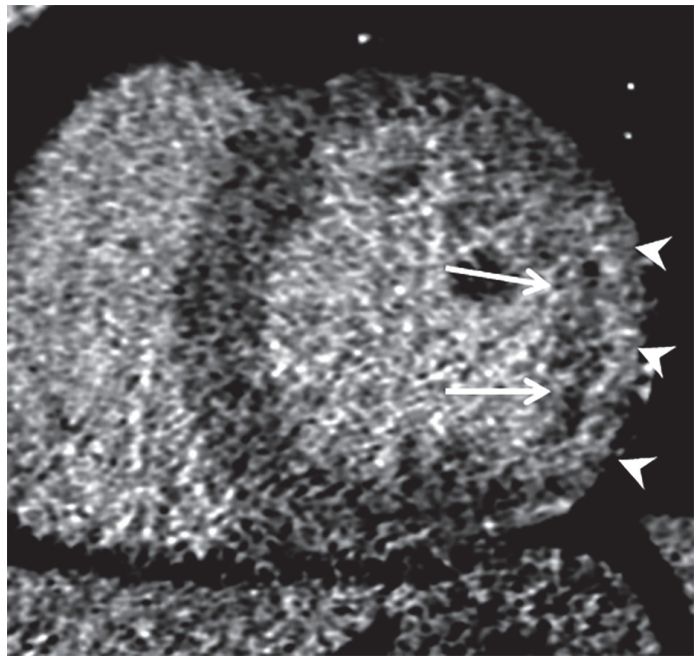

B

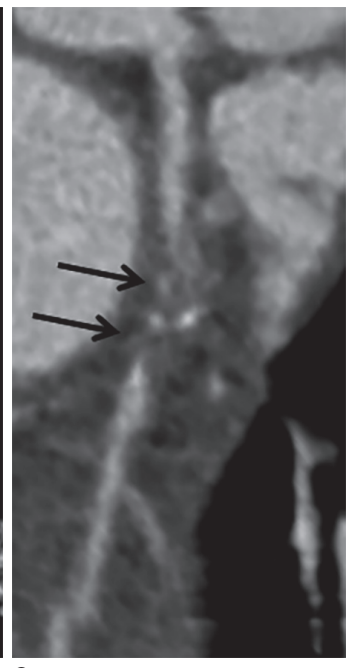

C

Fig. 3. Infarct imaging using first pass and delayed-enhancement CCT in patient with acute MI in left circumflex territory. Short-axis MPR images of first pass (A) and delayed enhancement (B) show fixed subendocardial perfusion defect (arrows) and delayed transmural hyperenhancement (arrowheads) in mid-lateral LV wall. Curved MPR coronary CT angiography image (C) shows acute thrombotic occlusion (arrows) of proximal left circumflex artery. Subendocardial perfusion defect indicates microvascular occlusion and poor prognosis. $\mathrm{MI}=$ myocardial infarction

after contrast administration (delayed-enhancement CCT), multiplied by (1-hematocrit). This protocol can be added to routine CCT with only a small increase in radiation dose. It can be used to delineate the myocardial interstitium and provides a new diagnostic test for an under-diagnosed and treatable cause of LV hypertrophy (LVH) and heart failure $(24,25)$. CCT represents a potential approach to the clinical assessment of diffuse myocardial fibrosis, particularly in patients with contraindications to CMR imaging. The drawback of delayed-enhancement CCT is the increased image noise and scan time. The multi-energy CCT can help to reduce the image noise and increase the contrast-tonoise ratio (21).

There are 4 different types of multi-energy scanners available in clinical practice for tissue characterization, as follows. 1) Dual-source technology: two X-ray tubes are operated at different $k V p$ values (for example, 80 and 140 kVp); 2) Rapid kVp switching technology: The X-ray source switches rapidly between low $(80 \mathrm{kVp})$ and high energy (140 kVp) levels at each X-ray projection; 3) Dual spin technology: Using a 320-detector-row CT scanner, the patient is initially scanned at one energy level (135 kVp) and immediately scanned in the same anatomic location using a different energy level (80 kVp); 4) Dual layer or spectral detector technology: CT contains one $\mathrm{X}$-ray source but two layers of detectors with the top layer absorbing low energy photons and the bottom layer absorbing high energy photons. Multi-energy CT allows the mapping of iodine distribution in the myocardium serving as a marker of myocardial perfusion (26-28). Delayed iodine enhancement imaging has the potential to better evaluate myocardial enhancement, which is considered a marker of myocardial fibrosis or scarring and detect myocardial infarction (MI) and non-ischemic cardiomyopathy more accurately than conventional CT. In addition, multi-energy CT enhanced the diagnosis of myocardial fibrosis by calculating the ECV fraction. Lee et al. (25) demonstrated that the myocardial ECV fraction determined with dual-energy equilibrium contrast-enhanced CCT was consistent with that of CMR imaging and excellent interobserver agreement in persubject analysis was observed.

\section{Analysis of LV Function}

The quantification of LV function using CCT has been validated in prior studies via comparison with echocardiography and CMR (29). In normal Korean adults, Kang et al. (30) demonstrated that the LV myocardial thickness (septal wall thickness, $1.08 \pm 0.18 \mathrm{~cm}$ vs. $0.90 \pm$ $0.17 \mathrm{~cm}$; posterior wall thickness, $0.91 \pm 0.15 \mathrm{~cm}$ vs. 0.78 $\pm 0.10 \mathrm{~cm})$, LV end-diastolic volume $(112.9 \pm 26.1 \mathrm{~mL}$ vs. $98.2 \pm 21.0 \mathrm{~mL})$, LV end-systolic volume $(41.7 \pm 14.7 \mathrm{~mL}$ vs. $33.7 \pm 12.2 \mathrm{~mL})$, and mass $(145.0 \pm 29.1 \mathrm{~g}$ vs. $107.9 \pm 20.0$ g) were significantly greater in men than in women when using 320-detector-row CCT, even though these significant differences disappeared after normalization for body 
surface area. The measurement of LV functional parameters by CCT can be used as an alternative, particularly in cases of equivocal or suboptimal echocardiography or contraindications for CMR. However, there is not sufficient evidence to recommend CCT as a routine measurement of LV functional parameters $(11,12)$. A wide-detector CT scanner with single shot scanning or dual-source $\mathrm{CT}$ encompassing both cardiac cycles may be used routinely for simultaneous functional analyses.

\section{Approach for LV Myocardial Diseases}

The evaluation of LV myocardial diseases using the CCT is based on LV volumes and function, regional LV wall motion, LV wall thickness, and myocardial density with and without contrast enhancement (Fig. 4). Generally, image acquisition in CCT is performed in mid-diastole to identify coronary anomalies or stenoses. Accordingly, interpretation of LV diameters and wall thickness may be inadequate, unless correct ECG timing is considered at the point of acquisition. Nonetheless, in the presence of definite morphological abnormalities such as LV wall asymmetry or distinct hypertrophy or thinning, the diagnosis may be apparent even when the acquisition phase is technically incorrect (1).

\section{Wall Thickness}

Measuring LV myocardial thickness is critical for the diagnosis and characterization of many cardiovascular diseases. Normal values for LV myocardial thickness published in the current literature are derived from echocardiography and CMR. The thickness of the myocardium is commonly measured at the interventricular septum at end-diastole. LV trabeculations are excluded from the measurement. The reference range of the LV septal and posterior wall thickness at end-diastole using echocardiography is $0.6-0.9 \mathrm{~cm}$ in women and $0.6-1.0$ $\mathrm{cm}$ in men (31). In normal Korean adults, the mean LV myocardial wall thickness measured on CCT was less than 11 $\mathrm{mm}$ at the septum and $10 \mathrm{~mm}$ at the posterior wall (30).

\section{Diseases Associated with LV Wall Hypertrophy}

LVH, defined by the increase in LV mass and LV septal wall thickness, is a common cardiac finding generally caused by a hemodynamic overload. LVH severity is graded based on LV septal wall thickness, indexed LV mass, and LV geometry. The reference values for LVH severity in clinical guidelines, which are based on echocardiographic measurements, are also used for CMR and CCT (31-33).

$\mathrm{LVH}$, frequently defined by interventricular septal and/ or posterior wall thickness at end-diastole $>11 \mathrm{~mm}$, is a marker for cardiac disease. LVH is a common pathology which requires exhaustive characterization. The exact diagnosis and differential diagnosis of LVH is of paramount therapeutic and prognostic value. Physiological LVH occurs in athletes (Athlete's heart). Pathological LVH is mainly classified into the primary (hypertrophic cardiomyopathy; HCM) and secondary types. LVH results in an increased afterload (aortic stenosis [AS], aortic insufficiency, and hypertension) or myocardial infiltration (amyloidosis,

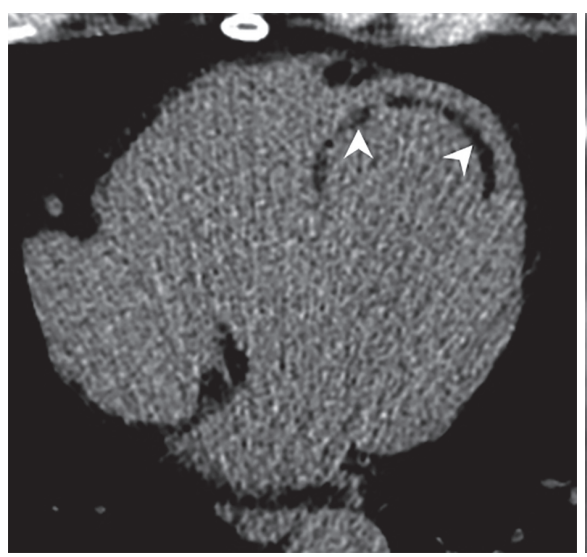

A

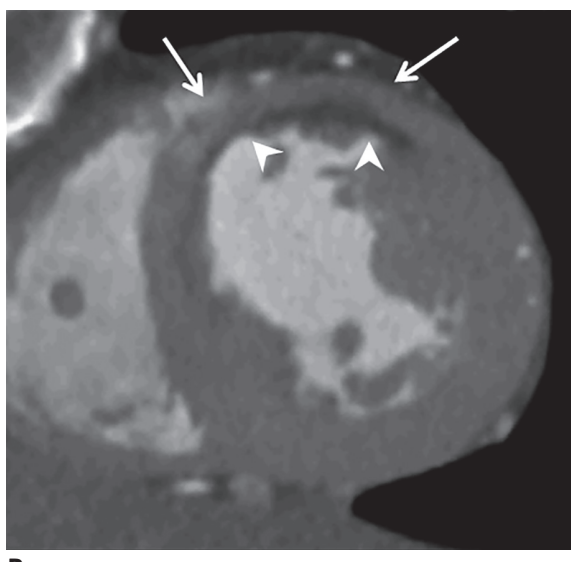

B

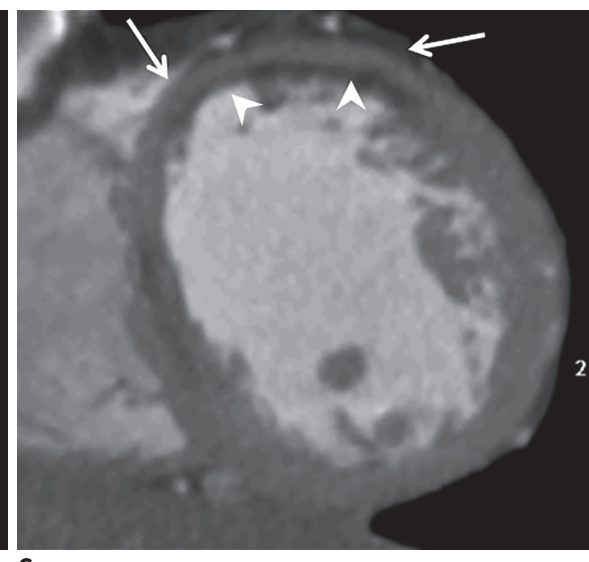

C

Fig. 4. Global and regional LV function assessment with CCT in 51-year-old man with previous MI.

Precontrast CCT image (A) shows curvilinear fat deposition in subendocardium of LV myocardium (arrowheads). Short-axis MPR CCT images obtained during end-systole (B) and end-diastole (C) show akinesia, curvilinear fat deposition in subendocardium (arrowheads), and thinned myocardium ( $5 \mathrm{~mm}$ in thickness) in mid-anterior and anteroseptal LV wall (arrows). LV ejection fraction, end-diastolic, and end-systolic volumes were $57 \%, 137 \mathrm{~mL}$, and $59 \mathrm{~mL}$, respectively. 


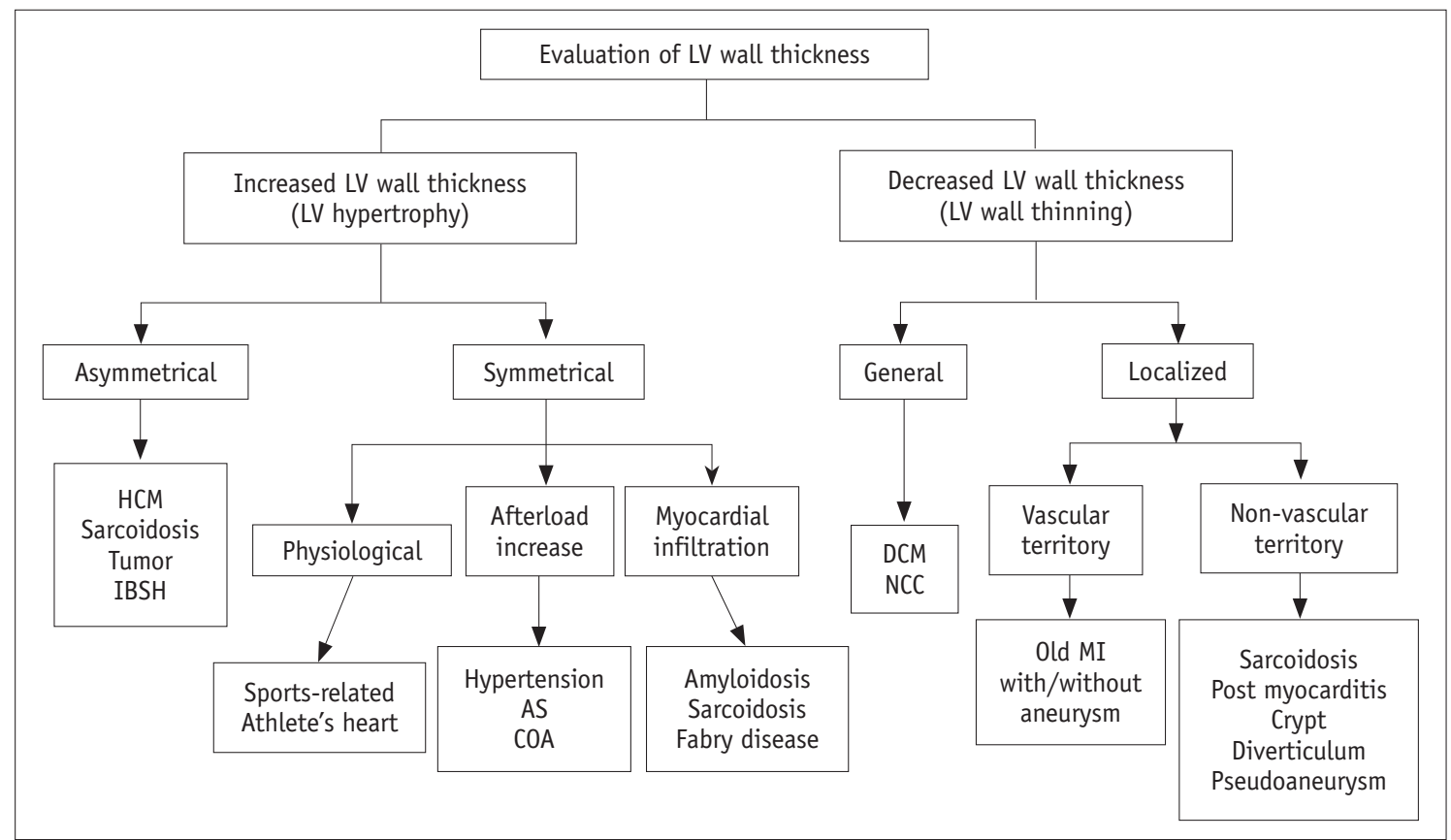

Fig. 5. Diagnostic approach based on LV wall thickness using CCT.

$\mathrm{AS}=$ aortic stenosis, $\mathrm{COA}=$ coarctation of aorta, $\mathrm{DCM}=$ dilated cardiomyopathy, $\mathrm{HCM}=$ hypertrophic cardiomyopathy, IBSH $=$ isolated basal septal hypertrophy, NCC = non-compaction cardiomyopathy

sarcoidosis, Fabry disease, and cardiac tumors) (33). The basic diagnostic approach for LVH depends on the morphological characteristics of LVH (symmetrical vs. asymmetrical) (Fig. 5).

\section{Asymmetrical LVH}

\section{Isolated Basal Septal Hypertrophy}

Isolated basal septal hypertrophy (IBSH) involving at least $15 \mathrm{~mm}$ thickness is occasionally termed a sigmoid septum or septal bulge. It is detected in up to $10 \%$ of cardiac patients without HCM and is more prevalent in the elderly population (34). In a study by Ranasinghe et al. (35), the presence of IBSH was strongly related to age with the observed frequency rising from $1 \%$ of people younger than 50 years to almost $10 \%$ in those aged $80-90$ years. The frequency of IBSH morphology was 14-fold higher than the frequency of typical morphological forms of HCM, and $65 \%$ of patients had a history of hypertension. A few patients with IBSH manifest exertional LV outflow tract (LVOT) obstruction and dyspnea, leading to difficulty in differentiating IBSH from HCM (35). In a study by Gaudron et al. (36) the echocardiographic septal bulge, defined as the basal-septal wall thickness $\geq 2 \mathrm{~mm}$ thicker than the mid-septal wall thickness, strongly predicted hypertension with a sensitivity of $93 \%$ and specificity of $86 \%$. The septal bulge in patients with hypertension is a very early sign of hypertensive heart disease. The LVOT and basal-to-middle interventricular septum are clearly visualized on 3-chamber and short-axis multiplanar reformatted (MPR) images of ECG-gated CCT (Fig. 6).

Hypertrophic Cardiomyopathy

$\mathrm{HCM}$ is the most common inheritable primary cardiomyopathy that is characterized by unexplained diffuse or segmental LVH without compensatory dilatation of the LV chamber, and with normal or supernormal systolic function (37). Progression to end-stage HCM, known as the burnout or dilated phase, is characterized by systolic dysfunction, LV dilatation, and wall thinning; it occurs in $2.4 \%$ to $15.7 \%$ of individuals and is associated with largely unfavorable prognosis $(38,39)$. The usual diagnostic criterion for HCM is LV maximal wall thickness $\geq 15 \mathrm{~mm}$ at the end-diastolic phase. Particularly, LV maximal wall thickness $\geq 30 \mathrm{~mm}$ is associated with sudden cardiac death (40). The most common form of HCM is asymmetric septal hypertrophy, which is defined as hypertrophy with a septalto-inferolateral wall thickness ratio $\geq 1.3$. Other forms of HCM are focal mass-like, mid-ventricular, and apical (41-43). CCT is more accurate than transthoracic echocardiography to detect LVH, particularly for the anterior-lateral free wall and for the apex. CCT plays a potential role in the assessment of HCM based on key morphological characteristics, LV systolic 
function, the extent of myocardial fibrosis with delayedenhancement (diffuse or focal enhancement with patchy or massive mid-wall), ECV measurement, and the presence of LV crypts as well as coronary artery evaluation simultaneously (Fig. 7). CCT reveals a thin-walled apical aneurysm showing transmural enhancement and intracavitary thrombus in

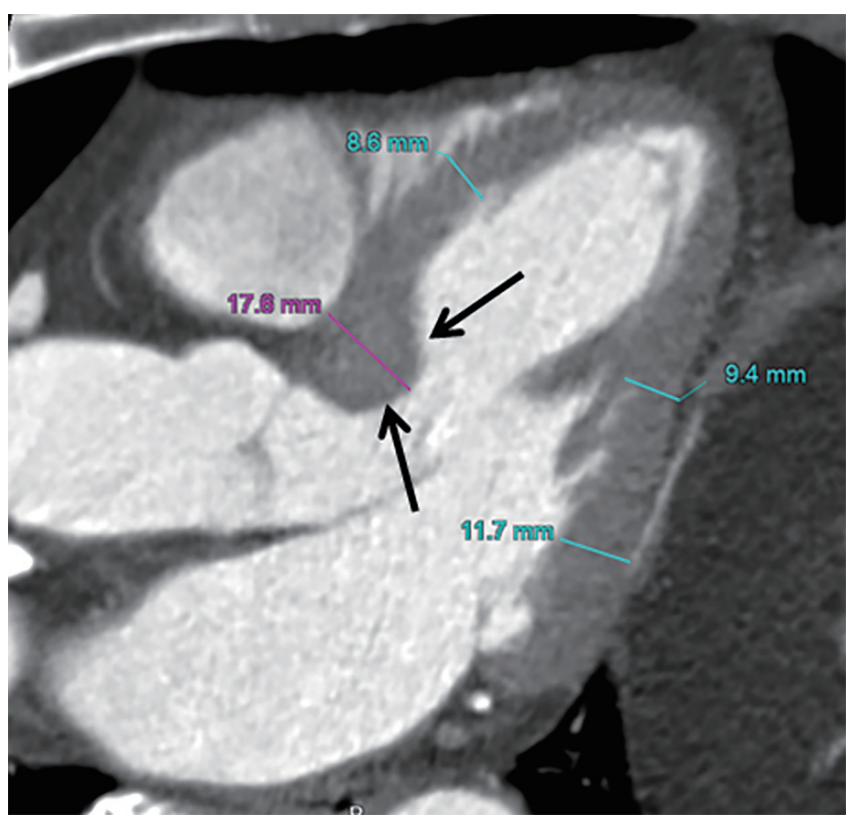

Fig. 6. IBSH of 67-year-old man with diabetes mellitus without hypertension. Three-chamber MPR CCT image shows focal hypertrophy of basal inter-ventricular septum (arrows) without hypertrophy elsewhere within myocardium in mid-diastole on LV outflow tract. patients with apical HCM with burned-out phase $(42,43)$.

\section{Sarcoidosis}

Sarcoidosis is a multisystemic disorder of unknown cause that is characterized histopathologically by noncaseous epithelioid granulomas. Granulomas and/or fibrous scars tend to be distributed in the subepicardial layer; however, they can be present anywhere in the myocardium. LVH in a noncoronary distribution is frequent and it mimics $\mathrm{HCM}$ with asymmetric focal LVH. Sarcoid lesions ultimately heal through fibrosis, which leads to myocardial thinning and ventricular aneurysm. The myocardial thickness fluctuates according to disease activity, with the myocardium thicker during the active phase and thinner during the healed phase. Thus, it may be difficult to distinguish cardiac sarcoidosis from other cardiomyopathies based on delayedenhancement pattern and myocardial thickness (44-46). CCT reveals the typical morphological features and delayedenhancement (multifocal segments with transmural or subepicardial distribution) in cardiac sarcoidosis, as well as its involvement in other organs (Fig. 8) (47).

\section{Cardiac Tumor}

Primary or secondary tumors located in the left ventricle lead to localized LVH. Primary cardiac tumors are rare, and the histological types are varied. The incidence of metastatic cardiac tumors is 100 -fold more common than that of primary tumors. Myocardial involvement is a less
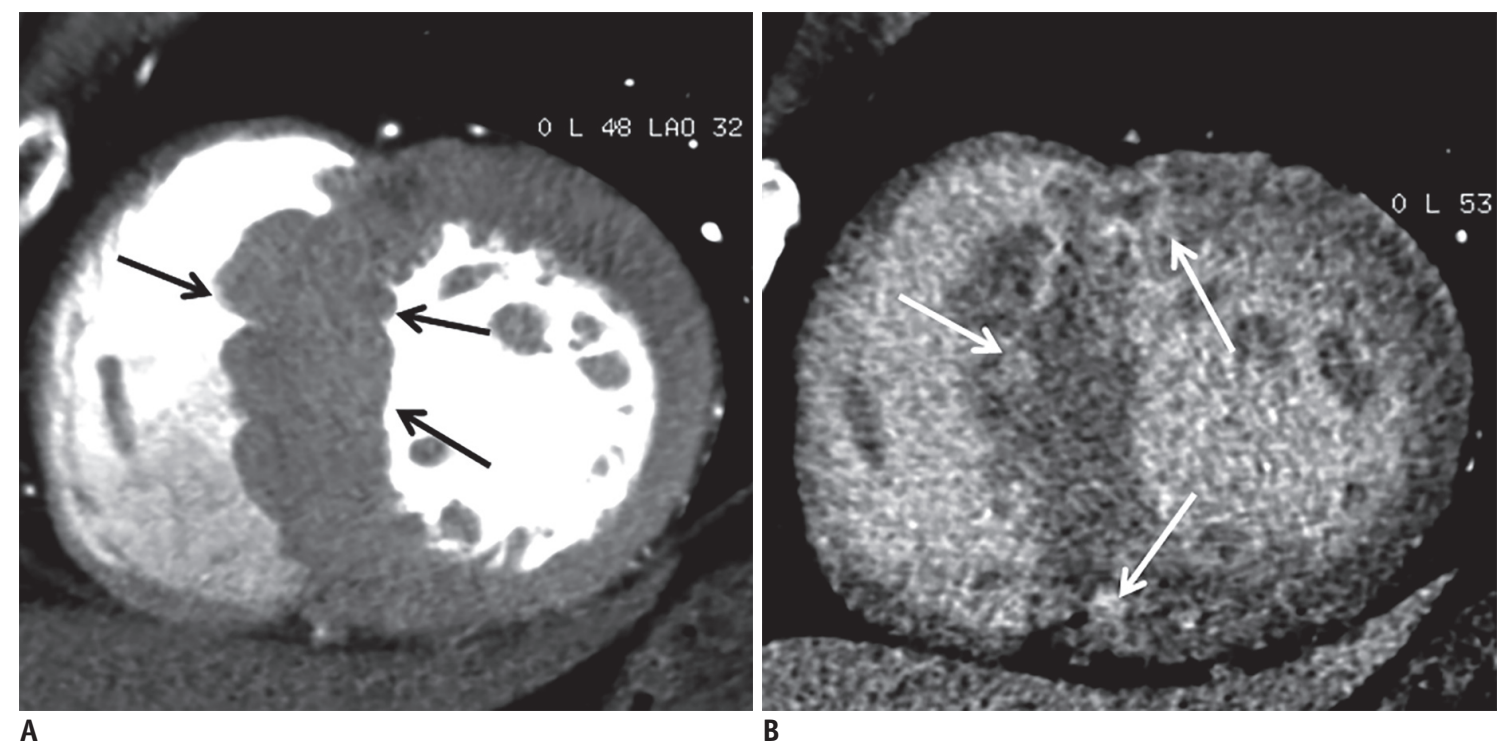

Fig. 7. HCM in 57-year-old man with chest pain.

Short-axis MPR CCT images obtained during early (A) and delayed (B) contrast-enhancement phases show asymmetrical hypertrophy of mid anterior, anteroseptal, and anterolateral LV wall (A, arrows) in mid-diastole with multifocal mid-wall delayed enhancement (B, arrows). 


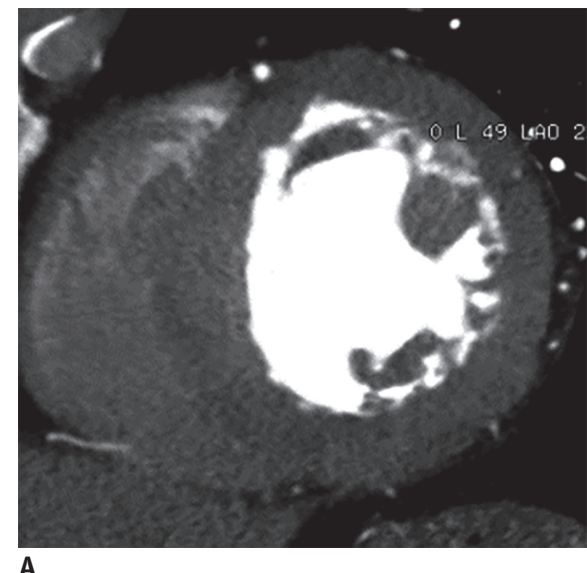

A

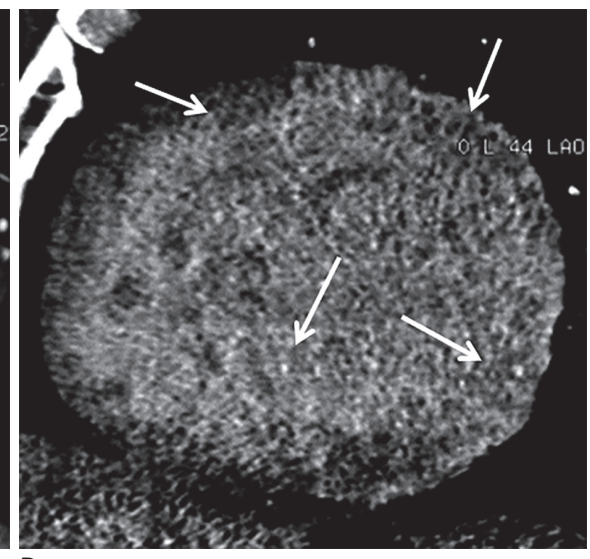

B

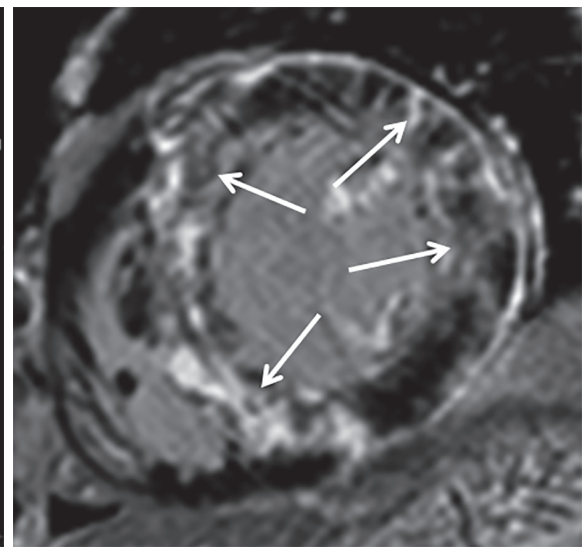

C

Fig. 8. Cardiac sarcoidosis in 61-year-old woman with irregular cardiac rhythm and dyspnea.

Short-axis MPR CCT images obtained during early (A) and delayed (B) contrast-enhancement phases show concentrically hypertrophied midLV wall in mid-diastole with diffuse transmural and mesocardial delayed enhancement (arrows). Delayed-enhancement CMR image (C) shows diffuse mesocardial enhancement in septum and multifocal patchy mesocardial enhancement in mid anterior, lateral, and inferior LV wall (arrows). Delayed-enhancement CMR is superior to delayed-enhancement CCT for differentiating patterns of delayed myocardial enhancement. CMR = cardiovascular magnetic resonance

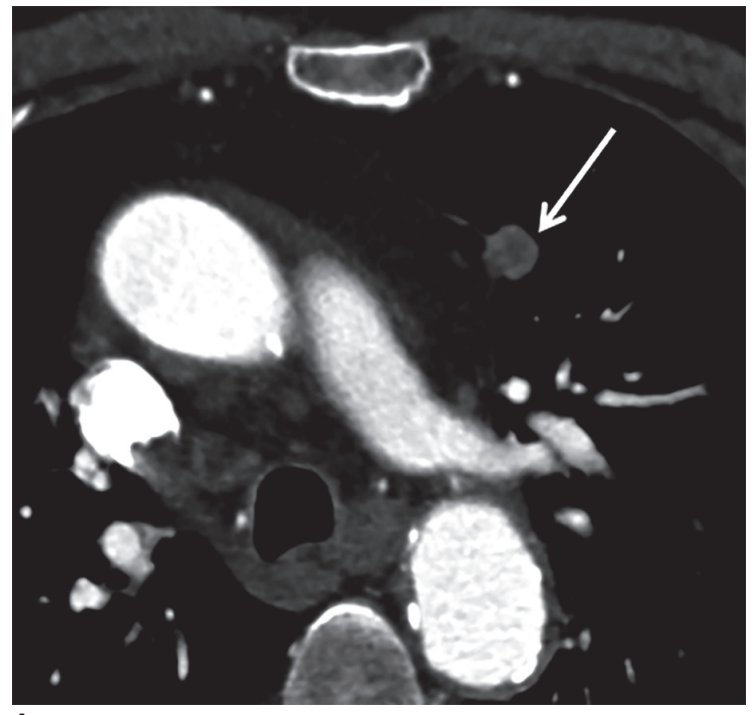

A

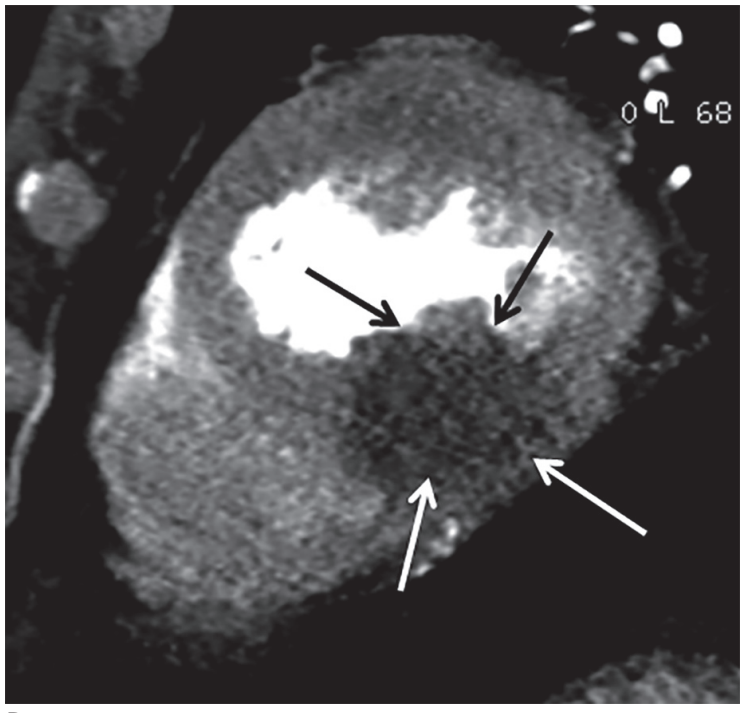

B

Fig. 9. LV metastasis from lung cancer in 93-year-old man.

Contrast-enhanced chest CT image (A) shows 13-mm lobulated nodule with heterogeneous enhancement in anterior segment of left lower lobe (arrow). Mid-diastolic short-axis MPR CCT image (B) shows large infiltrating mass with homogeneous hypoenhancement as focal hypertrophied mid inferoseptal and inferior LV wall (arrows).

common site of cardiac metastasis (Fig. 9). Benign cardiac tumors such as fibroma and rhabdomyoma are homogeneous masses with soft tissue attenuation, smooth and welldefined margins without infiltration. However, malignant tumors such as rhabdomyosarcoma and angiosarcoma show lobular, ill-defined, and invasive borders and a broad attachment to the myocardium. Primary cardiac lymphomas with massive myocardial infiltration may show irregular thickening of the LV wall that mimic classic HCM (48). CCT may facilitate the differentiation between cardiac tumor of the LV myocardium and mass-like HCM.

\section{Symmetrical LVH}

\section{Sports-Related LVH: 'Athlete's Heart'}

The term 'athlete's heart' refers to a clinical picture characterized by a lower heart rate and cardiac enlargement. Long-term exercise training-induced hemodynamic changes lead to an increase in both LV dilation and LVH, in order to normalize LV wall stress. Accordingly, athlete's heart 


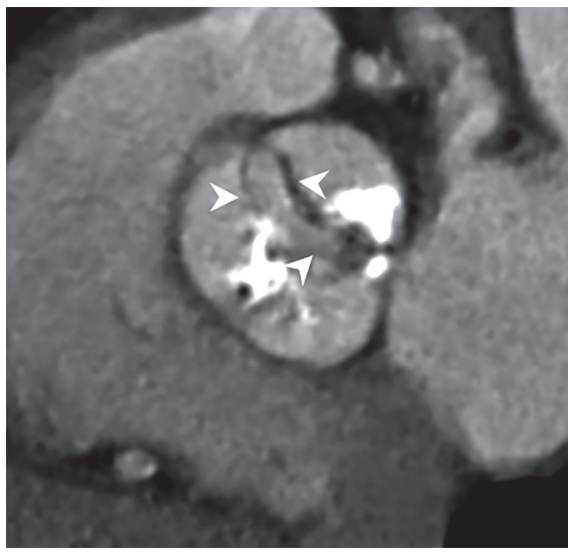

A

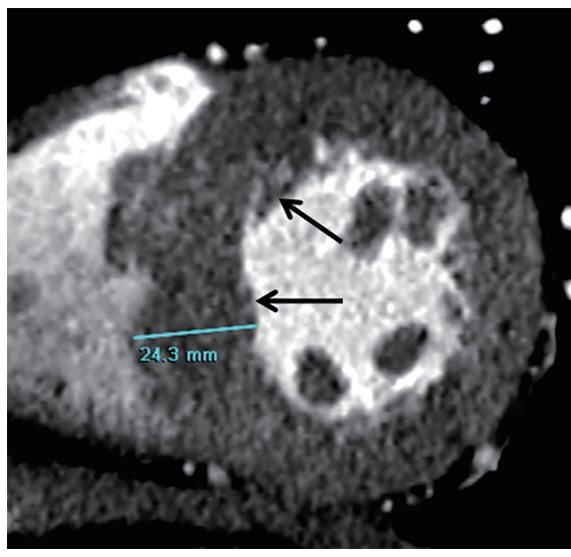

B

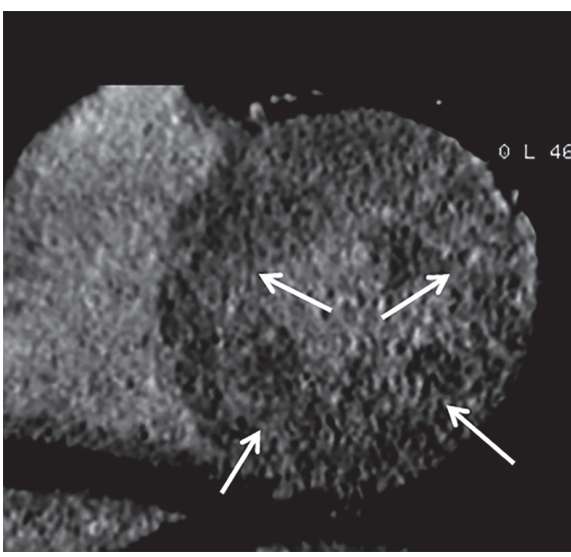

C

Fig. 10. Severe aortic valve stenosis in 79-year-old man with chest discomfort and shortness of breath.

Double oblique MPR image of aortic valve (A) shows thickened and calcified cusps (arrowheads) of tricuspid aortic valve with severely reduced opening (aortic valve area of $0.98 \mathrm{~cm}^{2}$ ) during early-systole. Short-axis MPR image (B) shows hypertrophied mid-LV wall, particularly asymmetric septal hypertrophy (arrows). Delayed-enhancement CCT image (C) shows extensive mesocardial delayed hyperenhancement in middle LV wall (arrows).

can mimic diseases such as HCM or dilated cardiomyopathy (DCM). In elite athletes, the LV end-diastolic diameter is not frequently increased to $>60 \mathrm{~mm}$ (49). In 947 elite athletes, the maximal end-diastolic septal wall thickness was $\leq 12 \mathrm{~mm}$ in most (50). CCT may be used to rule out coronary anomalies or coronary artery diseases (CAD) in symptomatic athletes (51).

\section{Hypertension}

Hypertension is a highly prevalent cardiovascular risk factor and it is the most common cause of LVH. Echocardiographic LVH is detected in $20-40 \%$ of patients with hypertension. Hypertensive heart usually shows concentric LVH, which is characterized by normal cavity size, uniformly increased LV wall thickness and increased LV mass. Interventricular septal thickness increases up to $15 \mathrm{~mm}$. Left atrial dilatation is also seen in hypertension $(52,53)$. In a study by Rodrigues et al. $(54)$, an asymmetric end-diastolic wall thickness of $\geq 15 \mathrm{~mm}$ and $>1.5$-fold the opposing myocardial segment in $\geq 1$ segment was exclusively observed in the basal-to-mid septum in $21 \%$ of a purely hypertensive cohort. CCT is appropriate for LV wall thickness, mass and volume measurement, and for excluding $C A D$ in patients with hypertension.

\section{Aortic Stenosis}

AS is the most common valvular heart disease (VHD) in the elderly population. AS increases LV afterload and causes compensatory LVH (concentric LVH). LVH causes reversible myocardial ischemia and irreversible myocardial injury, such as interstitial myocardial fibrosis (55). Accordingly, it is increasingly clear that it is also a disease of the left ventricle rather than the aortic valve exclusively. Usually, the LV wall is symmetrically hypertrophied in AS and, occasionally, an area of the LV shows asymmetrical septal hypertrophy (Fig. 10) (56). In a study by Tuseth et al. (57), asymmetrical septal hypertrophy (defined as interventricular septal/posterior wall thickness ratio $>1.5$ on echocardiography) was found in $22 \%$ of 1719 patients with asymptomatic AS and hypertension was the most important predictor of asymmetrical septal hypertrophy and asymmetric LVH.

CCT is a useful imaging modality for severe AS patients indicated for transcatheter aortic valve replacement. The assessment of LV function and scar imaging of the myocardium with CCT has not been routinely established in clinical practice (56). Recently, Bandula et al. (24) demonstrated a significant correlation between both equilibrium CT-derived and equilibrium CMR imaging-derived ECV and percentage of histological fibrosis in patients with severe AS. Equilibrium CT-derived ECV was significantly correlated to equilibrium CMR imaging-derived ECV.

\section{Amyloidosis}

Amyloidosis is a systemic disease characterized by the extracellular deposition of pathological and insoluble amyloid protein in multiple organs. Approximately 50\% of patients with immunoglobulin light-chain amyloidosis develop cardiac involvement. Cardiac amyloidosis is associated with poor prognosis. Myocardial thickening with a restrictive diastolic filling pattern is pathognomonic of cardiac amyloidosis. A diffusely heterogeneous delayed 
hyperenhancement along the areas of amyloid protein deposition, predominantly affecting the subendocardium and the basal segments, is more specific than the morphologic and functional findings $(58,59)$. CCT reveals thickening and subtle lower attenuation of the ventricular wall without dilatation. Subendocardial and circumferential delayed-enhancement is apparent on delayed-enhancement CCT (Fig. 11) (47). In a study by Deux et al. (60), myocardial attenuation on delayed-enhancement CCT was higher in patients with cardiac amyloidosis $(121 \pm 39 \mathrm{HU})$ than in control patients ( $81 \pm 17 \mathrm{HU})$. Dynamic equilibrium CT recently showed that the ECV was higher in patients with amyloidosis than with AS $(0.54 \pm 0.11$ vs. $0.28 \pm 0.04, p<$ 0.001 ) with no overlap and the ECV tracked clinical markers of cardiac amyloid severity (6). Accordingly, CCT, like CMR, has a potential role in the non-invasive diagnosis and quantification of cardiac amyloidosis.

\section{Diseases Associated with LV Wall Thinning}

Myocardium thinning is one of the principal signs of myocardial damage and ischemia. Even though old MI is the most common disease characterized by focal LV myocardial thinning, normal anatomical and congenital LV wall thinning and other non-coronary heart diseases also exhibit focal LV myocardial thinning (1). Several studies

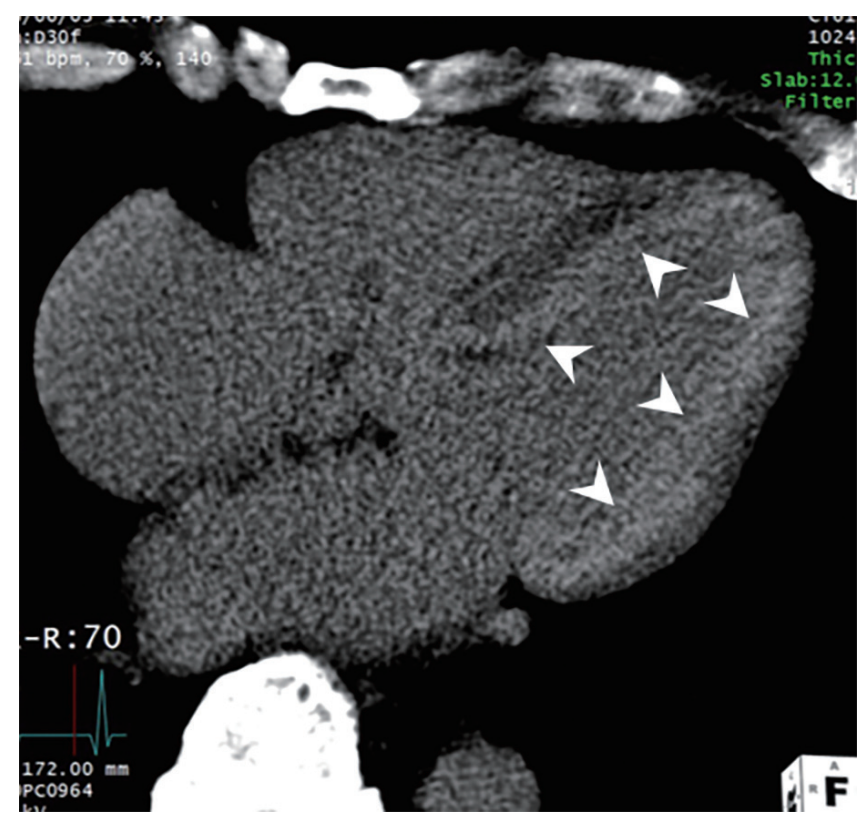

Fig. 11. Cardiac amyloidosis in 74-year-old male who presented with chest pain. Four-chamber MPR delayed enhancement image obtained during mid-diastole shows hypertrophy of LV myocardial wall and diffuse, concentric subendocardial and transmural enhancement (arrowheads) in LV myocardial wall. Case courtesy of HJ Lee, Yonsei University Severance Hospital. have focused on the presence of focal thinning as nonviable scar tissue in conventional cardiac imaging $(61,62)$.

CCT facilitates the differential diagnosis of LV myocardial thinning based on the location, asynergy, and presence of fibro-fatty changes of thinned LV sites (Fig. 5) (63).

\section{Global LV Wall Thinning}

Dilated cardiomyopathy

DCM, the most common form of non-ischemic cardiomyopathy, is characterized by a dilated and poorly functioning left ventricle in the absence of $C A D$, pressure overload, or infiltrative cardiomyopathies. Half of the cases are idiopathic in nature, with the remainder secondary to previous infection, alcohol and drug abuse, or toxicity. Sudden cardiac death, which accounts for $10 \%$ of all adult sudden cardiac death cases, may be the first manifestation of idiopathic DCM (64).

LV dilatation is a key finding of DCM and is occasionally associated with right ventricular dilatation and hypertrabeculation of both ventricles. The thickness of the LV wall increases or decreases to compensate for the dilatation. Occasionally, intracavitary thrombi are present in the ventricles. Three types of DCM-related delayed-enhancement include mid-wall, subendocardial, or transmural. The absence of delayed-enhancement has also been reported $(65,66)$. CCT has been used to evaluate the biventricular volumes, wall thinning (diastolic wall thickness $<5.5 \mathrm{~mm}$ ), ventricular mass, and global and regional LV functions using the multiphase reconstruction of cine images (Fig. 12). Furthermore, CCT allows for the characterization of the myocardium and the differentiation of DCM patients from LV dysfunction related to CAD by providing myocardial delayed-enhancement pattern and ECV values of the myocardium $(25,47)$.

\section{Non-Compaction Cardiomyopathy}

Non-compaction cardiomyopathy (NCC) is characterized by the presence of an abnormal noncompacted myocardium due to the arrested development of endomyocardial compaction. Its prevalence is $0.05 \%$ in the general population (67). The morphological findings of NCC are numerous and manifest as prominent trabeculations and deep intertrabecular recesses that communicate with the LV cavity but not with the coronary arteries $(68,69)$. The most frequently involved segments include the apical and midventricular areas of the inferior and lateral walls of the left 


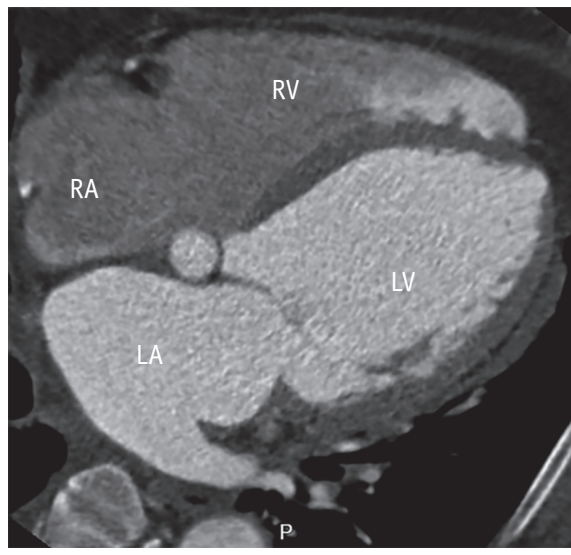

A

Fig. 12. DCM in 63-year-old man.

Four-chamber MPR image (A) obtained during end-diastole shows all cardiac chamber dilatation. Short-axis MPR CCT images obtained during end-systole (B) and end-diastole (C) show LV dilation, thinned myocardium (5 $\mathrm{mm}$ in thickness), and global severe hypokinesia. LV ejection fraction, end-diastolic, and end-systolic volumes were $12 \%, 137 \mathrm{~mL}$, and $59 \mathrm{~mL}$, respectively.

ventricle. The high spatial resolution of CCT facilitates clear depiction of trabeculations along the LV wall and LV crypt thrombus and it also facilitates an accurate measurement of the end-diastolic thickness of the noncompacted and compacted myocardium perpendicular to the compacted layers of the LV wall (Fig. 13) (70). Melendez-Ramirez et al. (71) demonstrated that the presence of a non-compactedto-compacted ratio $\geq 2.2$ in $\geq 2$ myocardial segments is diagnostic of NCC. The thickness of the compacted layer was significantly lower in the segments with NCC compared with the segments without it.

\section{Localized LV wall Thinning}

\section{Myocardial Infarction}

MI is a major cause of death and disability worldwide (72). The primary cause of acute MI is the sudden disruption of an unstable atherosclerotic plaque in the coronary artery followed by acute intracoronary thrombosis. The infarct progresses from the subendocardium towards the epicardium in a wavefront pattern, which may eventually become transmural. Regional wall thinning is indicative of transmural MI which affects the full thickness of the affected muscle segments (73).

Non-contrast CCT facilitates the detection of chronic MI displaying fatty replacement with lower attenuation (HU $<0$ ) or myocardial calcification in chronic MI territories. Ichikawa et al. (74) demonstrated the presence of adipose tissue in the LV wall ( $94 \%$ subendocardium) of the region perfused by the infarct-related artery in 33 of $53 \mathrm{MI}$ patients $(62 \%)$ and identified a significant relationship

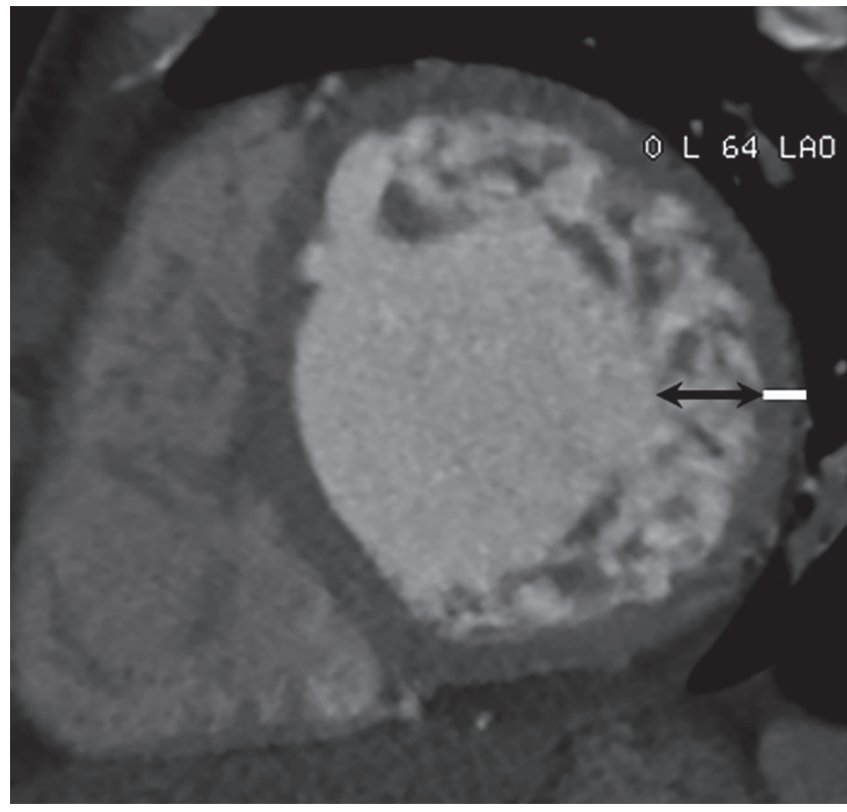

Fig. 13. NCC in 48-year-old woman with dyspnea and cough pain. End-diastolic short-axis MPR image shows increased thickness of noncompacted layer in anterior, lateral, and inferior segments of midLV wall with ratio of noncompacted (black arrow, $15 \mathrm{~mm}$ in thickness) to compacted myocardium (white line, $6 \mathrm{~mm}$ in thickness) $>2.3: 1$.

with infarct age in patients with previous MI, particularly among patients with infarct age $\geq 3$ years. Early-phase contrast-enhanced CCT shows hypoenhancement due to the reduced distribution of contrast medium during the first passage in infarcted areas of patients with acute, chronic, and subacute MI. Remodeling of the left ventricle, focal wall thinning, regional LV wall motion abnormality, or LV thrombus or aneurysm may be easily apparent on earlyphase CT $(75,76)$. Simple measurement of end-diastolic wall 
thickness $(<6 \mathrm{~mm})$ indicates irreversible myocardial damage and obviates the need for viability testing such as delayedenhancement CMR (77). Nieman et al. (78) demonstrated a significantly lower $\mathrm{CT}$ attenuation in patients with chronic MI $(-13 \pm 37 \mathrm{HU})$ compared with those with acute MI (26 $\pm 26 \mathrm{HU})$ and normal controls $(73 \pm 14 \mathrm{HU}, p<0.001)$. The attenuation difference between infarcted and remote myocardium was larger in patients with chronic MI than in patients with recent MI. In addition, chronic MI was associated with wall thinning and ventricular dilation, whereas recent MI was not. Cury et al. (79) showed that comprehensive $\mathrm{CT}$ analysis for the detection of acute MI, based on matching perfusion defect and abnormal regional wall motion, yielded a sensitivity of $94 \%$ and a specificity of $97 \%$ and showed that the interobserver reliability was better with $\mathrm{CT}$ when compared with transthoracic echocardiography.

Delayed-enhancement CCT ranging from 5 to 15 minutes after the contrast injection led to an accurate estimation of infarct size and microvascular occlusion in acute MI (80). Sato et al. (81) demonstrated that the size of myocardialdelayed enhancement on CCT images obtained immediately after primary percutaneous coronary intervention was a significant and independent predictor of cardiac events after adjustment for Thrombolysis In Myocardial Infarction risk score, LV ejection fraction, total defect score on singlephoton emission CT with technetium tetrofosmin, and transmural extent of delayed-enhancement on CCT. The feasibility and short examination time of CCT are considered important advantages when compared with CMR.

\section{Aneurysm}

LV aneurysm is defined as an outpouching containing full thickness of the LV wall with thin, abnormally contracting and scarred myocardium with its characteristic paradoxical bulging or dyskinesia. LV aneurysm most frequently develops after transmural MI, usually involving the apical, the anterior, or the anterolateral wall (left anterior descending artery territory). CCT findings include broad neck (the ratio of the maximum diameter of the orifice to the maximum internal diameter of the cavity = $0.9-1.0)$, smooth transition from normal myocardium to thinned scarred myocardium (delayed-enhancement), and paradoxical expansion or dyskinesia. In addition, fatty replacement of the infarcted myocardial wall, calcification, and intraventricular thrombus formation may be seen in chronic aneurysms (Fig. 14). A true aneurysm has a lower

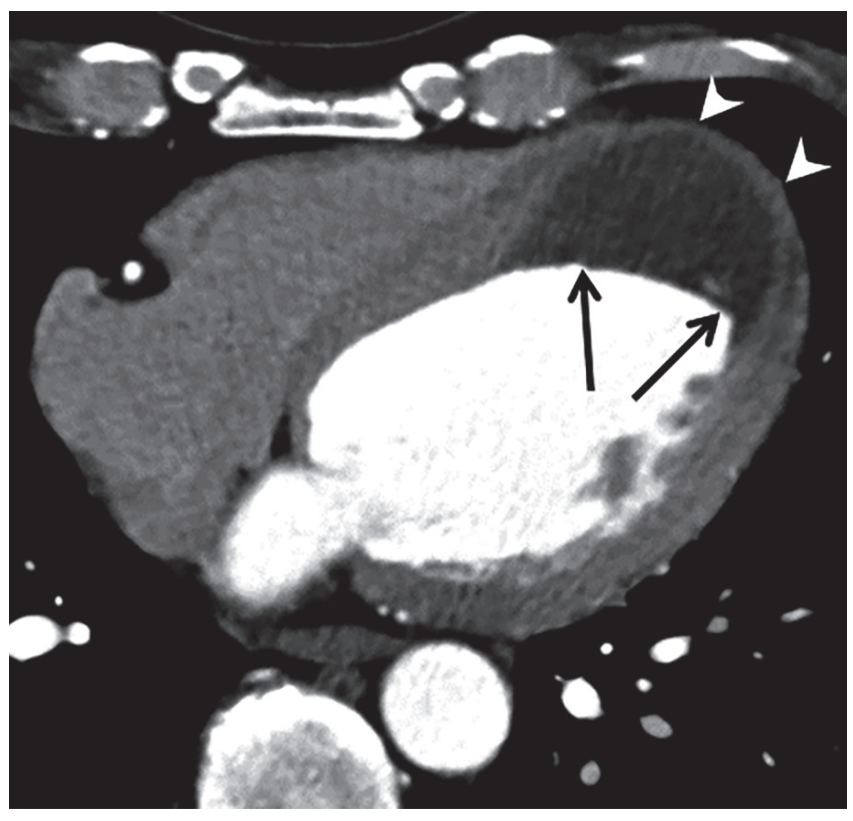

Fig. 14. LV aneurysm with intracavitary thrombus in 53-yearold man with chronic MI. Axial CCT image shows thin-walled apical aneurysm (arrowheads) and extensive intracavitary thrombus formation (arrows).

risk of rupturing when compared with a pseudoaneurysm and it is often managed medically $(82,83)$.

LV Pseudoaneurysm (a false aneurysm)

It is defined as an outpouching that results from rupture of the LV free wall, limited by an overlying adherent pericardium without a myocardial layer. Pseudoaneurysms are most often attributed to MI following left circumflex coronary artery occlusion. However, it may also occur after cardiac surgery, trauma, or infection (84). Morphologically, pseudoaneurysms are characterized by a neck narrower than the diameter of the aneurysm (the ratio of the maximum diameter of the orifice to the maximum internal diameter of the cavity $=0.25-0.5$ ), an abrupt transition from normal myocardium to aneurysm, and a distinct discontinuity of the ventricular wall. Generally, the inferior and lateral wall segments are involved (Fig. 15). Pseudoaneurysms have poor prognoses because of a high risk of rupture, thus warranting urgent surgical repair. CCT can distinguish between pericardium, thrombus, and the myocardium and it can identify akinetic/dyskinetic segments in the LV wall and provide diagnostic clues for LV aneurysms and pseudoaneurysms $(83,85)$.

\section{Apical Thin Point}

The LV apex is the thinnest part of the LV myocardium 
in normal and hypertrophied hearts and it is different from the cardiac apex (Fig. 1A) (86). Apical thickening is not observed throughout the entire cardiac cycle. This extreme tip of the apex is difficult to visualize on echocardiography but is clearly visible on CCT. In a study by Johnson et al. (87), the average thickness of the LV apical thinning was 1.2 $\mathrm{mm}$ in 64 patients using a 64-slice CT scanner. This normal

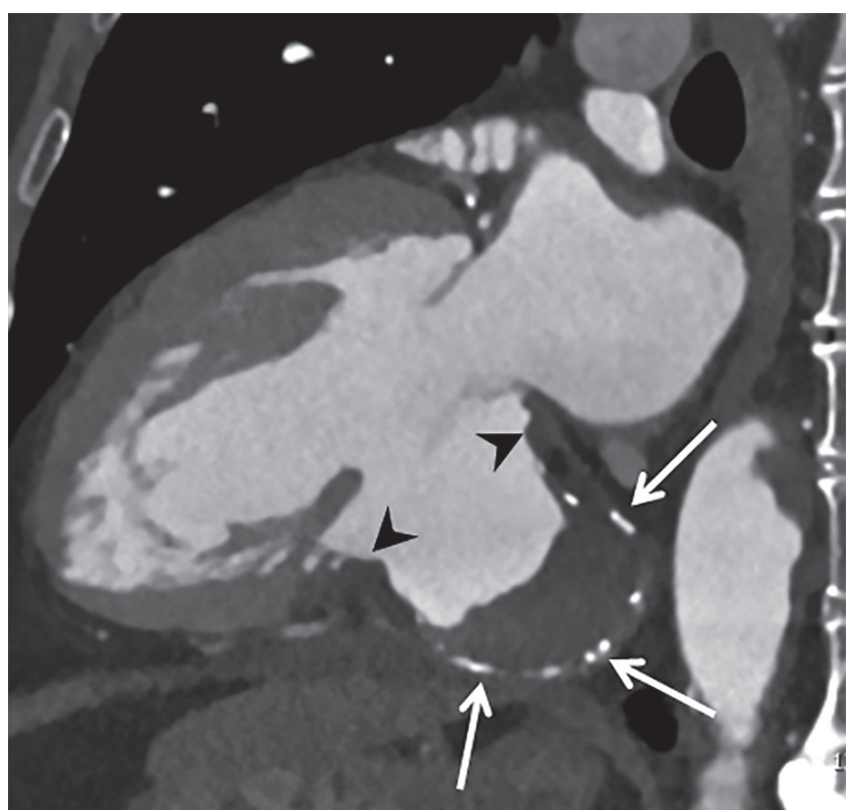

Fig. 15. LV pseudoaneurysm in 65-year-old man with stable angina. Two-chamber MPR CCT image shows LV inferior wall outpouching with relatively narrow neck (arrowheads), intracavitary thrombus (arrows), and multiple calcifications along its wall. anatomical thinning should not be confused with either a myocardial scar from an ischemic insult or a congenital LV diverticulum.

\section{Crypts}

Myocardial crypts are defined as narrow, deep bloodfilled invaginations in the compact LV myocardium with a penetration $>50 \%$ of the thickness of adjoining myocardium during diastole and are almost or completely obliterated by surrounding tissue during systole. They commonly involve the basal and middle segments of the inferoseptal LV myocardium, as well as the basal inferior wall and are reported in a wide variety of cardiac diseases as well as in normal control subjects (Fig. 16) (88). In a study by Child et al. (89), crypts were found more frequently in patients with hypertensive cardiomyopathy (27\%) and HCM (11.7\%) than in normal control subjects $(3.6 \%)$. Recent studies suggest that the presence of crypts in patients with an otherwise normal CMR and a family history of HCM was a predictor of 'gene carrier' status, with implications for genetic testing $(90,91)$. CCT is a highly sensitive imaging tool for the detection of myocardial crypts with MPR images from the isotropic volumetric data set covering all portions of the left ventricle.

\section{Congenital LV Diverticulum}

Congenital LV diverticulum is a rare cardiac malformation (approximately $0.04 \%$ in the general population). Despite

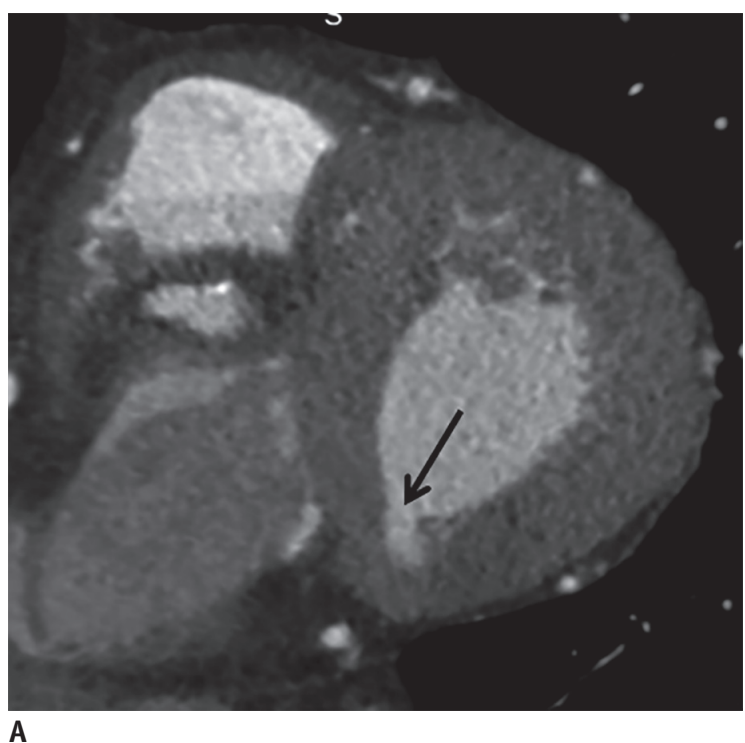

A

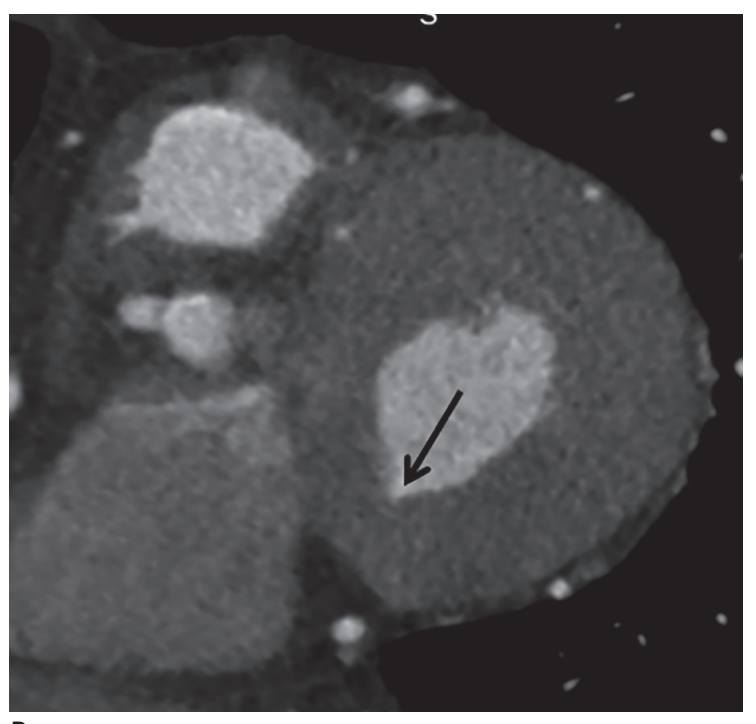

B

Fig. 16. LV crypt in 68-year-old man with HCM.

End-diastolic (A) and end-systolic short-axis (B) MPR CCT images show sharp-edged disruption of normal compacted myocardium penetrating basal inferior LV wall (A, arrow) with near complete obliteration during end-systole (B, arrow). 
the absence of symptoms, this malformation may be associated with systemic embolization, fatal ventricular arrhythmias, and sudden death due to ventricular rupture (92). Based on its location, this malformation can be classified as fibrous or muscular. The muscular diverticulum is more frequent and mostly found in the apical region. It is characterized by a finger or hook-like pouch of the entire LV myocardial wall with synchronous contractility (Fig. 17). The fibrous diverticulum is usually located either in the base of the heart or in the subvalvular area. It is characterized by an

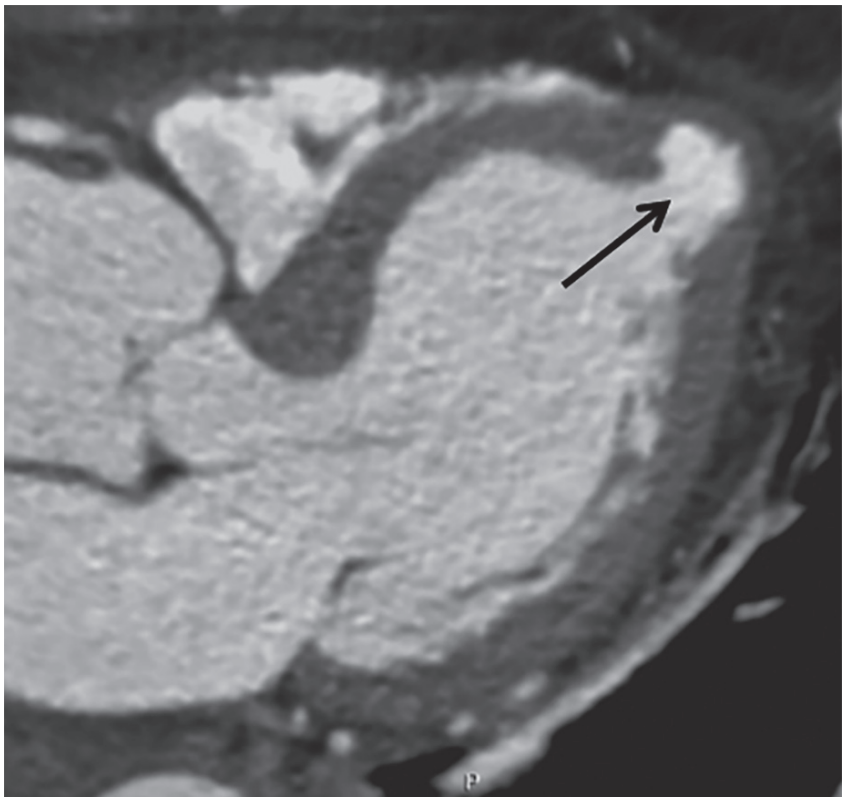

Fig. 17. LV diverticulum. Three-chamber MPR CCT image shows finger or hook-like pouch of entire LV myocardial wall (arrow) arising from LV apex in mid-diastole. outpouching with a narrow neck, no volume change during the cardiac cycle, and the presence of fibrous tissue on the diverticulum wall. CCT facilitates accurate diagnosis of LV diverticulum based on the location, tissue characteristics, and contractility of LV outpouching (93).

\section{Myocarditis}

Myocarditis is an acute or chronic inflammatory disease of the myocardium. It is an important etiology underlying other myocardial diseases such as DCM and arrhythmogenic right ventricular cardiomyopathy. Direct myocardial injury is accompanied by edema, necrosis, and regional or global contractile dysfunction. The late post-inflammatory fibrotic phase shows scar formation and irreversible damage to the LV wall, as well as LV dilatation (Fig. 18) (94-97).

In patients with acute chest pain, CCT may be used to exclude CAD. Delayed-enhancement CCT shows delayed hyper-enhancement that is transmural, subepicardial or confined to small foci within a layer of the myocardium. Delayed-enhancement CT correlates with CMR in acute myocarditis based on areas and degrees of involvement. $A$ reduced tube voltage increases the contrast of iodine and simultaneously lowers radiation exposure $(98,99)$.

\section{Myocardial Fat}

Adults generally display a varying amount of myocardial fat without cardiac disease. Physiological myocardial fat increases with age and it is considered as part of the normal aging process. Cardiac physiologic fat occurs predominantly in the right ventricle affecting its anterolateral free

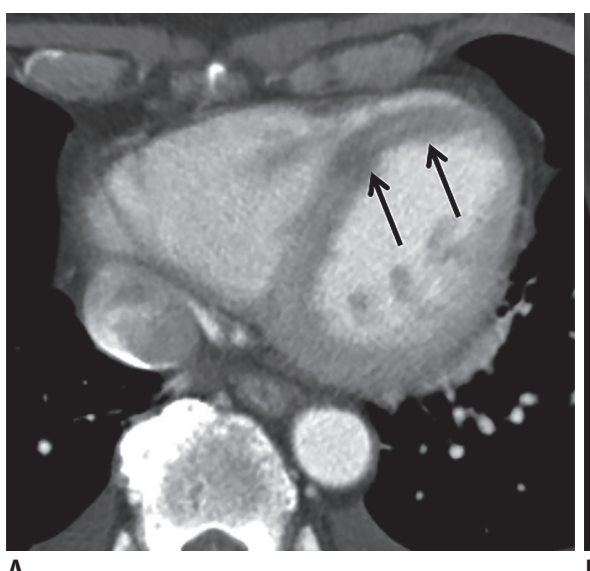

A
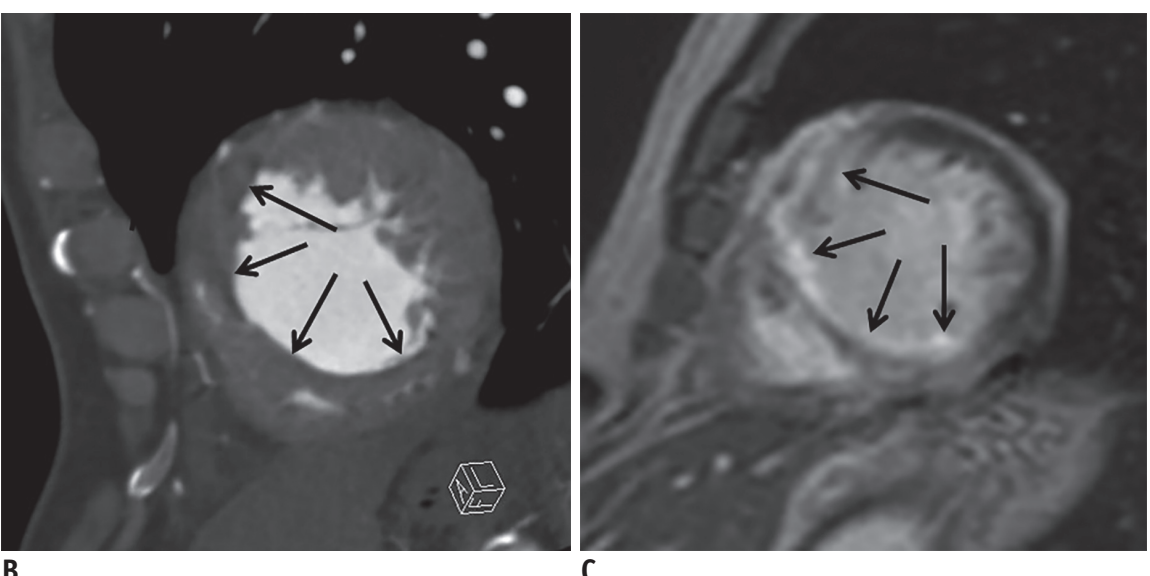

C

Fig. 18. Myocarditis in 69-year-old man with dyspnea for 10 days.

Initial chest CT (A) shows hypoenhancement in apical to mid interventricular septum (arrows) with preserved myocardial thickness. Short-axis MPR CCT image (B) obtained 3 weeks later shows thinned myocardium at anterior, septal, and inferior segments of middle LV wall (arrows). Delayed-enhancement cardiac magnetic resonance image (C) obtained 5 weeks later shows transmural hyperenhancement at mid-anterior and septal LV wall and subendocardial hyperenhancement at middle inferior LV wall (arrows). 
wall and outflow tract. Occasionally, the LV apex and trabeculae may be affected with small fatty foci (Fig. 19). CCT facilitates incidental detection of myocardial fat on source axial images of submillimeter thickness and aids the differentiation of pathologic from physiologic fat according to the characteristic fat patterns, leading to accurate diagnosis (100).

Recognition of patient age, characteristic locations of myocardial fat, myocardial thickness, and ventricular size facilitate the differentiation of physiological and pathological myocardial fat in cardiac imaging. Following MI, the scar tissue is progressively replaced by fat (lipomatous metaplasia). The fatty replacement is associated with infarct age and is frequently seen in infarctions older than three years but is absent in patients with less than 6-month-old infarcts. CT analysis shows that the prevalence of LV myocardial fat is $22-62 \%$ among patients with a history of MI. Non-enhanced or contrast-enhanced CT images show that myocardial fat associated with a healed MI is an area of linear or curvilinear subendocardial low attenuation in the culprit coronary artery, frequently in the LV. It is mostly located in the subendocardial myocardium. LV myocardial fat is also associated with myocardial thinning or calcification. LV myocardial fat in arrhythmogenic right ventricular cardiomyopathy appears as a wedge-shaped or bandlike configuration in the subepicardial LV-free wall on CT.

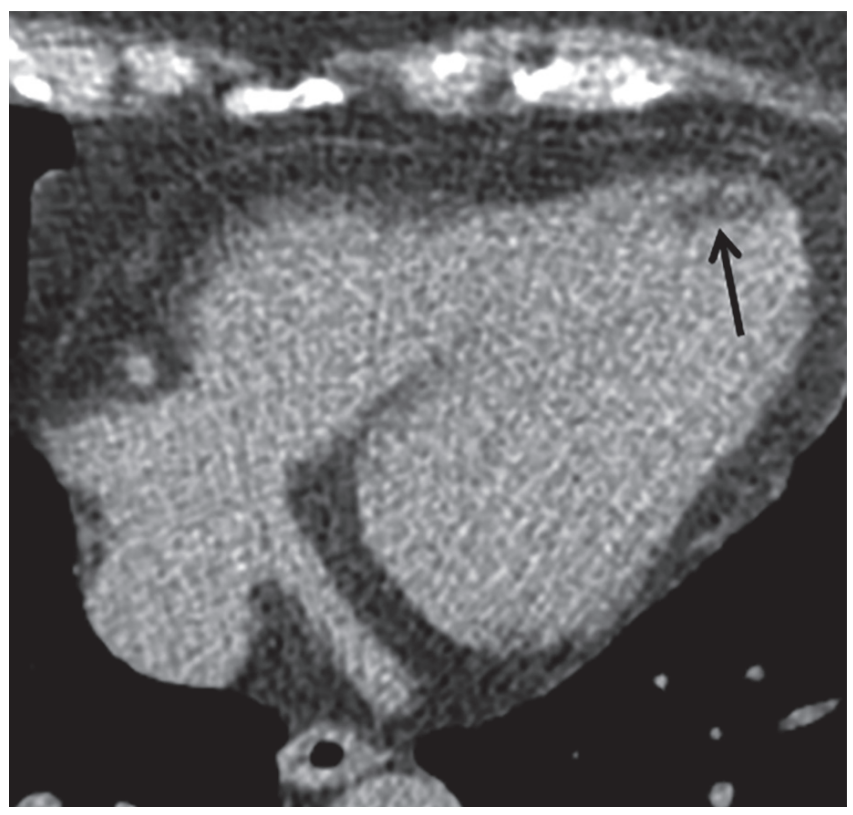

Fig. 19. Nonspecific myocardial fat in 51-year-old woman without cardiac symptoms. Axial precontrast CCT image shows fat (arrow) in LV apical septum.
Cardiac lipoma is a benign encapsulated tumor with mature adipose tissue and is usually located in the myocardium of any cardiac chambers as an asymptomatic fatty mass. DCM may also be associated with myocardial fat deposition in $18-24 \%$ of cases $(74,101-103)$.

\section{CONCLUSION}

The distinction between various LV myocardial diseases is of great significance as the management options vary considerably with the prognosis. Their characteristic features in various imaging modalities show considerable overlap. In many forms of myocardial disease, thickening and/or thinning of the LV myocardium with fibrosis is a common feature. CCT is inferior to CMR in differentiating myocardial diseases and myocardial fibrosis, except myocardial fat. Especially, most of the restrictive myocardial diseases can be normal on CCT. However, the higher spatial resolution and volumetric acquisition of CCT allows for the depiction of myocardial fat and morphological abnormality and has a promising role in the diagnosis of diseases affecting the LV myocardium. Recently, myocardial delayedenhancement CCT and multi-energy CCT have yielded promising results in the detection and characterization of various LV myocardial diseases. CCT has potential as an adjunct to echocardiography and CMR in the diagnosis of LV myocardial diseases in a single sitting.

\section{Conflicts of Interest}

The authors have no potential conflicts of interest to disclose.

ORCID iD

\section{Sung Min Ko}

https://orcid.org/0000-0002-7420-6269

\section{REFERENCES}

1. Clayton B, Roobottom C, Morgan-Hughes G. Assessment of the myocardium with cardiac computed tomography. Eur Heart J Cardiovasc Imaging 2014; 15:603-609

2. Prasad K, Atherton J, Smith GC, McKenna WJ, Frenneaux MP, Nihoyannopoulos P. Echocardiographic pitfalls in the diagnosis of hypertrophic cardiomyopathy. Heart 1999;82(suppl 3):III8-III15

3. Patel AR, Kramer CM. Role of cardiac magnetic resonance in the diagnosis and prognosis of nonischemic cardiomyopathy. JACC CardiovasC Imaging 2017;10:1180- 
1193

4. Captur G, Manisty C, Moon JC. Cardiac MRI evaluation of myocardial disease. Heart 2016;102:1429-1435

5. Machida H, Tanaka I, Fukui R, Shen Y, Ishikawa T, Tate E, et al. Current and novel imaging techniques in coronary CT. Radiographics 2015;35:991-1010

6. Treibel TA, Bandula S, Fontana M, White SK, Gilbertson $J A$, Herrey AS, et al. Extracellular volume quantification by dynamic equilibrium cardiac computed tomography incardiac amyloidosis. J Cardiovasc Comput Tomogr 2015;9:585-592

7. Ho SY. Anatomy and myoarchitecture of the left ventricular wall in normal and in disease. Eur J Echocardiogr 2009;10:iii3-7

8. Sengupta PP, Korinek J, Belohlavek M, Narula J, Vannan MA, Jahangir A, et al. Left ventricular structure and function: basic science for cardiac imaging. J Am Coll Cardiol 2006;48:1988-2001

9. O'Brien JP, Srichai MB, Hecht EM, Kim DC, Jacobs JE. Anatomy of the heart at multidetector CT: what the radiologist needs to know. Radiographics 2007;27:15691582

10. Cerqueira MD, Weissman NJ, Dilsizian V, Jacobs AK, Kaul S, Laskey WK, et al. Standardized myocardial segmentation and nomenclature for tomographic imaging of the heart. A statement for healthcare professionals from the cardiac imaging committee of the council on clinical cardiology of the American Heart Association. Circulation 2002;105:539542

11. Kim YJ, Yong HS, Kim SM, Kim JA, Yang DH, Hong YJ, et al. Korean guidelines for the appropriate use of cardiac CT. Korean J Radiol 2015;16:251-285

12. ASCI Practice Guideline Working Group, Beck KS, Kim JA, Choe YH, Hian SK, Hoe J, et al. 2017 multimodality appropriate use criteria for noninvasive cardiac imaging: expert consensus of the Asian Society of Cardiovascular Imaging. Korean J Radiol 2017;18:871-880

13. Sato A, Aonuma K. Role of cardiac multidetector computed tomography beyond coronary angiography. Circ J 2015;79:712-720

14. Abbara S, Blanke P, Maroules CD, Cheezum M, Choi AD, Han BK, et al. SCCT guidelines for the performance and acquisition of coronary computed tomographic angiography: a report of the society of cardiovascular computed tomography guidelines committee: endorsed by the North American Society for Cardiovascular Imaging (NASCI). J Cardiovasc Comput Tomogr 2016;10:435-449

15. Bischoff B, Bamberg F, Marcus R, Schwarz F, Becker HC, Becker A, et al. Optimal timing for first-pass stress CT myocardial perfusion imaging. Int J Cardiovasc Imaging 2013;29:435-442

16. Rossi A, Merkus D, Klotz E, Mollet N, de Feyter PJ, Krestin GP. Stress myocardial perfusion: imaging with multidetector CT. Radiology 2014;270:25-46
17. Yang DH, Kim YH, Roh JH, Kang JW, Han D, Jung J, et al. Stress myocardial perfusion CT in patients suspected of having coronary artery disease: visual and quantitative analysis-validation by using fractional flow reserve. Radiology 2015;276:715-723

18. Rossi A, Dharampal A, Wragg A, Davies LC, van Geuns RJ, Anagnostopoulos C, et al. Diagnostic performance of hyperaemic myocardial blood flow index obtained by dynamic computed tomography: does it predict functionally significant coronary lesions? Eur Heart J Cardiovasc Imaging 2014; $15: 85-94$

19. Ko SM, Kim YW, Han SW, Seo JB. Early and delayed myocardial enhancement in myocardial infarction using two-phase contrast-enhanced multidetector-row CT. Korean J Radiol 2007;8:94-102

20. Lardo AC, Cordeiro MA, Silva C, Amado LC, George RT, Saliaris AP, et al. Contrast-enhanced multidetector computed tomography viability imaging after myocardial infarction: characterization of myocyte death, microvascular obstruction, and chronic scar. Circulation 2006;113:394-404

21. Deseive S, Bauer RW, Lehmann R, Kettner M, Kaiser C, Korkusuz $\mathrm{H}$, et al. Dual-energy computed tomography for the detection of late enhancement in reperfused chronic infarction: a comparison to magnetic resonance imaging and histopathology in a porcine model. Invest Radiol 2011;46:450-456

22. Mahnken AH, Koos R, Katoh M, Wildberger JE, Spuentrup $E$, Buecker A, et al. Assessment of myocardial viability in reperfused acute myocardial infarction using 16-slice computed tomography in comparison to magnetic resonance imaging. J Am Coll Cardiol 2005;45:2042-2047

23. Gerber BL, Belge B, Legros GJ, Lim P, Poncelet A, Pasquet $A$, et al. Characterization of acute and chronic myocardial infarcts by multidetector computed tomography: comparison with contrast-enhanced magnetic resonance. Circulation 2006;113:823-833

24. Bandula S, White SK, Flett AS, Lawrence D, Pugliese F, Ashworth MT, et al. Measurement of myocardial extracellular volume fraction by using equilibrium contrast-enhanced CT: validation against histologic findings. Radiology 2013;269:396-403

25. Lee HJ, Im DJ, Youn JC, Chang S, Suh YJ, Hong YJ, et al. Myocardial extracellular volume fraction with dual-energy equilibrium contrast-enhanced cardiac CT in nonischemic cardiomyopathy: a prospective comparison with cardiac MR imaging. Radiology 2016;280:49-57

26. McCollough CH, Leng S, Yu L, Fletcher JG. Dual- and multienergy CT: principles, technical approaches, and clinical applications. Radiology 2015;276:637-653

27. Kalisz K, Halliburton S, Abbara S, Leipsic JA, Albrecht MH, Schoepf UJ, et al. Update on cardiovascular applications of multienergy CT. Radiographics 2017;37:1955-1974

28. Ko SM, Song MG, Chee HK, Hwang HK, Feuchtner GM, Min JK. Diagnostic performance of dual-energy CT 
stress myocardial perfusion imaging: direct comparison with cardiovascular MRI. AJR Am J Roentgenol 2014;203:W605-W613

29. Asferg C, Usinger L, Kristensen TS, Abdulla J. Accuracy of multi-slice computed tomography for measurement of left for measurement of left ventricular ejection compared with cardiac magnetic resonance imaging and two-dimensional transthoracic echocardiography: a systematic review and meta-analysis. Eur J Radiol 2012;81:e757-762

30. Kang EJ, Lee KN, Choi WJ, Kim YD, Shin KM, Lim JK, et al. Left ventricular functional parameters and geometric patterns in Korean adults on coronary CT angiography with a 320-detector-row CT scanner. Korean J Radiol 2017;18:664-673

31. Lang RM, Badano LP, Mor-Avi V, Afilalo J, Armstrong A, Ernande $L$, et al. Recommendations for cardiac chamber quantification by echocardiography in adults: an update from the American Society of Echocardiography and the European Association of Cardiovascular Imaging. Eur Heart J Cardiovasc Imaging 2015;16:233-271

32. Barbieri A, Bursi F, Mantovani F, Valenti C, Quaglia M, Berti $E$, et al. Left ventricular hypertrophy reclassification and death: application of the recommendation of the American Society of Echocardiography/European Association of Echocardiography. Eur Heart J Cardiovasc Imaging 2012;13:109-117

33. Alkema M, Spitzer E, Soliman OI, Loewe C. Multimodality imaging for left ventricular hypertrophy severity grading: a methodological review. J Cardiovasc Ultrasound 2016;24:257-267

34. Kelshiker MA, Mayet J, Unsworth B, Okonko D0. Basal septal hypertrophy. Curr Cardiol Rev 2013;9:325-330

35. Ranasinghe I, Ayoub C, Cheruvu C, Freedman SB, Yiannikas J. Isolated hypertrophy of the basal ventricular septum: characteristics of patients with and without outflow tract obstruction. Int J Cardiol 2014;173:487-493

36. Gaudron PD, Liu D, Scholz F, Hu K, Florescu C, Herrmann $S$, et al. The septal bulge--an early echocardiographic sign in hypertensive heart disease. J Am Soc Hypertens 2016;10:70-80

37. Cardim N, Galderisi M, Edvardsen T, Plein S, Popescu BA, D'Andrea A, et al. Role of multimodality cardiac imaging in the management of patients with hypertrophic cardiomyopathy: an expert consensus of the European Association of Cardiovascular Imaging Endorsed by the Saudi Heart Association. Eur Heart J Cardiovasc Imaging 2015;16:280

38. Biagini E, Coccolo F, Ferlito M, Perugini E, Rocchi G, Bacchi-Reggiani $L$, et al. Dilated-hypokinetic evolution of hypertrophic cardiomyopathy: prevalence, incidence, risk factors, and prognostic implications in pediatric and adult patients. J Am Coll Cardiol 2005;46:1543-1550

39. Harris KM, Spirito P, Maron MS, Zenovich AG, Formisano $F$, Lesser JR, et al. Prevalence, clinical profile, and significance of left ventricular remodeling in the endstage phase of hypertrophic cardiomyopathy. Circulation 2006;114:216-225

40. Olivotto I, Gistri R, Petrone P, Pedemonte E, Vargiu $D$, Cecchi F. Maximum left ventricular thickness and risk of sudden death in patients with hypertrophic cardiomyopathy. J Am Coll Cardiol 2003;41:315-321

41. Kim SS, Ko SM, Choi SI, Choi BH, Stillman AE. Sudden cardiac death from structural heart diseases in adults: imaging findings with cardiovascular computed tomography and magnetic resonance. Int J Cardiovasc Imaging 2016;32 Suppl 1:21-43

42. Chun EJ, Choi SI, Jin KN, Kwag HJ, Kim YJ, Choi BW, et al. Hypertrophic cardiomyopathy: assessment with MR imaging and multidetector CT. Radiographics 2010;30:1309-1328

43. Hashimura H, Kimura F, Ishibashi-Ueda H, Morita Y, Higashi M, Nakano S, et al. Radiologic-pathologic correlation of primary and secondary cardiomyopathies: MR imaging and histopathologic findings in hearts from autopsy and transplantation. Radiographics 2017;37:719-736

44. Blankstein R, Waller AH. Evaluation of known or suspected cardiac sarcoidosis. Circ Cardiovasc Imaging 2016;9:e000867

45. Isobe M, Tezuka D. Isolated cardiac sarcoidosis: clinical characteristics, diagnosis and treatment. Int $\mathrm{J}$ Cardiol 2015;182:132-140

46. Kusano KF, Satomi K. Diagnosis and treatment of cardiac sarcoidosis. Heart 2016;102:184-190

47. Lee HJ, Im DJ, Youn JC, Chang S, Suh YJ, Hong YJ, et al. Assessment of myocardial delayed enhancement with cardiac computed tomography in cardiomyopathies: a prospective comparison with delayed enhancement cardiac magnetic resonance imaging. Int J Cardiovasc Imaging 2017;33:577584

48. Chiles C, Woodard PK, Gutierrez FR, Link KM. Metastatic involvement of the heart and pericardium: CT and MR imaging. Radiographics 2001;21:439-449

49. Galderisi M, Cardim N, D’Andrea A, Bruder 0, Cosyns $B$, Davin $L$, et al. The multi-modality cardiac imaging approach to the athlete's heart: an expert consensus of the European Association of Cardiovascular Imaging. Eur Heart J Cardiovasc Imaging 2015;16:353

50. Spirito P, Pelliccia A, Proschan MA, Granata M, Spataro A, Bellone $P$, et al. Morphology of the "'athlete"s heart' assessed by echocardiography in 947 elites athletes representing 27 sports. Am J Cardiol 1994;74:802-806

51. Gräni C, Buechel RR, Kaufmann PA, Kwong RY. Multimodality imaging in individuals with anomalous coronary arteries. JACC Cardiovasc Imaging 2017;10:471-481

52. Marwick TH, Gillebert TC, Aurigemma G, Chirinos J, Derumeaux G, Galderisi M, et al. Recommendations on the use of echocardiography in adult hypertension: a report from the European Association of Cardiovascular Imaging (EACVI) and the American Society of Echocardiography (ASE). Eur Heart J Cardiovasc Imaging 2015;16:577-605 
53. Maceira AM, Mohiaddin RH. Cardiovascular magnetic resonance in systemic hypertension. J Cardiovasc Magn Reson 2012;14:28

54. Rodrigues JC, Amadu AM, Dastidar AG, Hassan N, Lyen SM, Lawton $C B$, et al. Prevalence and predictors of asymmetric hypertensive heart disease: insights from cardiac and aortic function with cardiovascular magnetic resonance. Eur Heart $\mathrm{J}$ Cardiovasc Imaging 2016;17:1405-1413

55. Maganti K, Rigolin VH, Sarano ME, Bonow RO. Valvular heart disease: diagnosis and management. Mayo Clin Proc 2010;85:483-500

56. Badiani S, van Zalen J, Treibel TA, Bhattacharyya S, Moon JC, Lloyd G. Aortic stenosis, a left ventricular disease: insights from advanced imaging. Curr Cardiol Rep 2016;18:80

57. Tuseth N, Cramariuc D, Rieck AE, Wachtell K, Gerdts E. Asymmetric septal hypertrophy - a marker of hypertension in aortic stenosis (a SEAS substudy). Blood Press 2010;19:140-144

58. Czeyda-Pommersheim F, Hwang M, Chen SS, Strollo D, Fuhrman C, Bhalla S. Amyloidosis: modern cross-sectional imaging. Radiographics 2015;35:1381-1392

59. Bhogal S, Ladia V, Sitwala P, Cook E, Bajaj K, Ramu V, et al. Cardiac amyloidosis: an updated review with emphasis on diagnosis and future directions. Curr Probl Cardiol 2018;43:10-34

60. Deux JF, Mihalache CI, Legou F, Damy T, Mayer J, Rappeneau S, et al. Noninvasive detection of cardiac amyloidosis using delayed enhanced MDCT: a pilot study. Eur Radiol 2015;25:2291-2297

61. Shah DJ, Kim HW, James 0, Parker M, Wu E, Bonow RO, et al. Prevalence of regional myocardial thinning and relationship with myocardial scarring in patients with coronary artery disease. JAMA 2013;309:909-918

62. Komatsu Y, Cochet H, Jadidi A, Sacher F, Shah A, Derval N, et al. Regional myocardial wall thinning at multidetector computed tomography correlates to arrhythmogenic substrate in postinfarction ventricular tachycardia: assessment of structural and electrical substrate. Circ Arrhythm Electrophysiol 2013;6:342-350

63. Cisneros S, Duarte R, Fernandez-Perez GC, Castellon D, Calatayud J, Lecumberri I, et al. Left ventricular apical diseases. Insights Imaging 2011;2:471-482

64. Dec GW, Fuster V. Idiopathic dilated cardiomyopathy. N Engl J Med 1994;331:1564-1575

65. McCrohon JA, Moon JC, Prasad SK, McKenna WJ, Lorenz CH, Coats $A J$, et al. Differentiation of heart failure related to dilated cardiomyopathy and coronary artery disease using gadolinium-enhanced cardiovascular magnetic resonance. Circulation 2003;108:54-59

66. Nanjo S, Yoshikawa K, Harada M, Inoue Y, Namiki A, Nakano $\mathrm{H}$, et al. Correlation between left ventricular diastolic function and ejection fraction in dilated cardiomyopathy using magnetic resonance imaging with late gadolinium enhancement. Circ J 2009;73:1939-1944

67. Weiford BC, Subbarao VD, Mulhern KM. Noncompaction of the ventricular myocardium. Circulation 2004;109:2965-2971

68. Ritter M, Oechslin E, Sütsch G, Attenhofer C, Schneider J, Jenni R. Isolated noncompaction of the myocardium in adults. Mayo Clin Proc 1997;72:26-31

69. Freedom RM, Yoo SJ, Perrin D, Taylor G, Petersen S, Anderson $\mathrm{RH}$. The morphological spectrum of ventricular noncompaction. Cardiol Young 2005;15:345-364

70. Sidhu MS, Uthamalingam S, Ahmed W, Engel LC, Vorasettakarnkij Y, Lee AM, et al. Defining left ventricular noncompaction using cardiac computed tomography. $J$ Thorac Imaging 2014;29:60-66

71. Melendez-Ramirez G, Castillo-Castellon F, EspinolaZavaleta N, Meave A, Kimura-Hayama ET. Left ventricular noncompaction: a proposal of new diagnostic criteria by multidetector computed tomography. J Cardiovasc Comput Tomogr 2012;6:346-354

72. Roger VL, Go AS, Lloyd-Jones DM, Benjamin EJ, Berry JD, Borden WB, et al. Executive summary: heart disease and stroke statistics--2012 update: a report from the American Heart Association. Circulation 2012;125:188-197

73. Rajiah P, Desai MY, Kwon D, Flamm SD. MR imaging of myocardial infarction. Radiographics 2013;33:1383-1412

74. Ichikawa Y, Kitagawa K, Chino S, Ishida M, Matsuoka K, Tanigawa $T$, et al. Adipose tissue detected by multislice computed tomography in patients after myocardial infarction. JACC Cardiovasc Imaging 2009;2:548-555

75. La Grutta L, Toia P, Maffei E, Cademartiri F, Lagalla R, Midiri M. Infarct characterization using CT. Cardiovasc Diagn Ther 2017;7:171-188

76. Vliegenthart R, Henzler T, Moscariello A, Ruzsics B, Bastarrika G, Oudkerk $M$, et al. CT of coronary heart disease: part 1, CT of myocardial infarction, ischemia, and viability. AJR Am J Roentgenol 2012;198:531-547

77. Cwajg JM, Cwajg E, Nagueh SF, He ZX, Qureshi U, Olmos LI, et al. End-diastolic wall thickness as a predictor of recovery of function in myocardial hibernation: relation to restredistribution T1-201 tomography and dobutamine stress echocardiography. J Am Coll Cardiol 2000;35:1152-1161

78. Nieman K, Cury RC, Ferencik M, Nomura CH, Abbara S, Hoffmann U, et al. Differentiation of recent and chronic myocardial infarction by cardiac computed tomography. Am J Cardiol 2006;98:303-308

79. Cury RC, Nieman K, Shapiro MD, Butler J, Nomura CH, Ferencik $\mathrm{M}$, et al. Comprehensive assessment of myocardial perfusion defects, regional wall motion, and left ventricular function by using 64-section multidetector CT. Radiology 2008;248:466-475

80. Rodriguez-Granillo GA. Delayed enhancement cardiac computed tomography for the assessment of myocardial infarction: from bench to bedside. Cardiovasc Diagn Ther 2017;7:159-170

81. Sato A, Nozato T, Hikita H, Akiyama D, Nishina $H$, Hoshi 
T, et al. Prognostic value of myocardial contrast delayed enhancement with 64-slice multidetector computed tomography after acute myocardial infarction. $\mathrm{J} \mathrm{Am} \mathrm{Coll}$ Cardiol 2012;59:730-738

82. Sharma A, Kumar S. Overview of left ventricular outpouchings on cardiac magnetic resonance imaging. Cardiovasc Diagn Ther 2015;5:464-470

83. Makkuni P, Kotler MN, Figueredo VM. Diverticular and aneurysmal structures of the left ventricle in adults: report of a case within the context of a literature review. Tex Heart Inst J 2010;37:699-705

84. Frances C, Romero A, Grady D. Left ventricular pseudoaneurysm. J Am Coll Cardiol 1998;32:557-561

85. Sharma RK, Gore R, Rosen BD, Arbab-Zadeh A. Diagnosis of left ventricular pseudoaneurysm by cardiac CT angiography. J Cardiovasc Comput Tomogr 2014;8:246-247

86. Bradfield JW, Beck G, Vecht RJ. Left ventricular apical thin point. Br Heart J 1977;39:806-809

87. Johnson KM, Johnson HE, Dowe DA. Left ventricular apical thinning as normal anatomy. J Comput Assist Tomogr 2009;33:334-337

88. Deva DP, Williams LK, Care M, Siminovitch KA, Moshonov $H$, Wintersperger BJ, et al. Deep basal inferoseptal crypts occur more commonly in patients with hypertrophic cardiomyopathy due to disease-causing myofilament mutations. Radiology 2013;269:68-76

89. Child N, Muhr T, Sammut E, Dabir D, Ucar EA, Bueser T, et al. Prevalence of myocardial crypts in a large retrospective cohort study by cardiovascular magneticresonance. $J$ Cardiovasc Magn Reson 2014;16:66

90. Germans T, Wilde AA, Dijkmans PA, Chai W, Kamp 0, Pinto YM, et al. Structural abnormalities of the inferoseptal left ventricular wall detected by cardiac magnetic resonance imaging in carriers of hypertrophic cardiomyopathy mutations. J Am Coll Cardiol 2006;48:2518-2523

91. Maron MS, Rowin EJ, Lin D, Appelbaum E, Chan RH, Gibson CM, et al. Prevalence and clinical profile of myocardial crypts in hypertrophic cardiomyopathy. Circ Cardiovasc Imaging 2012;5:441-447

92. Ohlow MA. Congenital left ventricular aneurysms and diverticula: definition, pathophysiology, clinical relevance and treatment. Cardiology 2006;106:63-72

93. Romagnoli A, Ricci A, Morosetti D, Fusco A, Citraro D, Simonetti G. Congenital left ventricular diverticulum: multimodality imaging evaluation and literature review. J Saudi Heart Assoc 2015;27:61-67

94. Brunetti L, DeSantis ER. Treatment of viral myocarditis caused by coxsackievirus B. Am J Health Syst Pharm 2008; 65:132-137

95. Feldman AM, McNamara D. Myocarditis. N Engl J Med 2000;343:1388-1398

96. Okura Y, Dec GW, Hare JM, Kodama M, Berry GJ, Tazelaar $H D$, et al. A clinical and histopathologic comparison of cardiac sarcoidosis and idiopathic giant cell myocarditis. $J$ Am Coll Cardiol 2003;41:322-329

97. Drory Y, Turetz Y, Hiss Y, Lev B, Fisman EZ, Pines A, et al. Sudden unexpected death in persons less than 40 years of age. Am J Cardiol 1991;68:1388-1392

98. Axsom K, Lin F, Weinsaft JW, Min JK. Evaluation of myocarditis with delayed-enhancement computed tomography. J Cardiovasc Comput Tomogr 2009;3:409-411

99. Tröbs M, Brand M, Achenbach S, Marwan M. Ultra-low dose comprehensive cardiac CT imaging in a patient with acute myocarditis. J Cardiovasc Comput Tomogr 2014;8:475-476

100. Kimura F, Matsuo Y, Nakajima T, Nishikawa T, Kawamura S, Sannohe $S$, et al. Myocardial fat at cardiac imaging: how can we differentiate pathologic from physiologic fatty infiltration? Radiographics 2010;30:1587-1602

101. Kim SS, Ko SM, Song MG. Linear fat deposition in the middle layer of the left ventricular myocardium: computed tomographic findings. Korean J Radiol 2010;11:571-573

102. Kim SS, Ko SM, Song MG. Fat streak in the middle layer of the left ventricular myocardium in a patient with dilated cardiomyopathy: findings of multidetector CT and MR imaging. Int J Cardiovasc Imaging 2011;27:745-748

103. Zafar HM, Litt HI, Torigian DA. CT imaging features and frequency of left ventricular myocardial fat in patients with CT findings of chronic left ventricular myocardial infarction. Clin Radiol 2008;63:256-262 